\title{
Transient and non-uniform heat flux effect on solar thermoelectric generator with phase change material
}

\author{
Samson Shittu ${ }^{\mathrm{a}}$, Guiqiang Liª ${ }^{\mathrm{a} *}$ Guiqiang.Li@hull.ac.uk, Qindong Xuan ${ }^{\mathrm{b}}$, Xin Xiao ${ }^{\mathrm{a}}$, Xudong Zhao ${ }^{\mathrm{a}, *}$ \\ Xudong.Zhao@hull.ac.uk, Xiaoli Ma ${ }^{\mathrm{a}}$, Yousef Golizadeh Akhlaghi ${ }^{\mathrm{a}}$ \\ ${ }^{a}$ Centre for Sustainable Energy Technologies, University of Hull, HU6 7RX, UK \\ ${ }^{\mathbf{b}}$ Department of Thermal Science and Energy Engineering, University of Science and Technology of China, \\ 96 Jinzhai Road, Hefei City 230026, China \\ *Corresponding authors.
}

\begin{abstract}
Transient and non-uniform heat flux from solar concentrators can affect the performance of solar thermoelectric generators, which generate electricity from concentrated solar radiation. Therefore, this paper presents a detailed three-dimensional study on the effect of transient and non-uniform heat flux on the performance of a solar thermoelectric generator (STEG). COMSOL 5.4 Multiphysics software is utilized for the numerical study while the non-uniform heat flux from a compound parabolic concentrator is obtained through ray tracing simulation using Lighttools software. Varying solar radiation under typical partly cloudy weather condition is utilized. Furthermore, phase change material (PCM) is used to reduce the effect of transient and nonuniform heat flux therefore; it is positioned at the top surface of the solar thermoelectric generator. A comparison between the performance of the STEG with and without PCM is presented, and a parametric study on the effect of PCM fins and PCM height on the STEG performance is carried out. Results show that the place of PCM on the top surface of the solar thermoelectric generator is an effective approach to provide a stable electrical performance form the STEG under varying weather conditions. Furthermore, results reveal the effectiveness of the phase change material in protecting the solar thermoelectric generator under highly concentrated solar radiation. This study will provide valuable design guidance for solar thermoelectric generators under varying weather conditions and with solar concentrators, which produce non-uniform heat flux.
\end{abstract}

Keywords: Solar thermoelectric generator; Non-uniform heat flux; PCM; Finite element method; Transient study 


\section{Nomenclature}

\begin{tabular}{|c|c|}
\hline$A_{s}$ & area of SSA, $\mathrm{m}^{2}$ \\
\hline$A_{s}$ & area of SSA \\
\hline $\mathrm{C}$ & concentration ratio \\
\hline$C_{p}$ & specific heat capacity, $\mathrm{J} / \mathrm{kg} / \mathrm{K}$ \\
\hline G & solar radiation, $\mathrm{W} / \mathrm{m}^{2}$ \\
\hline $\mathrm{H}_{\text {container }}$ & PCM container height \\
\hline $\mathrm{H}_{\mathrm{pcm}}$ & PCM height \\
\hline$h$ & convective heat transfer coefficient, $\mathrm{W} /\left(\mathrm{m}^{2} \cdot \mathrm{K}\right)$ \\
\hline$h_{c}$ & thermal contact conductance, $\mathrm{W} /\left(\mathrm{m}^{2} \cdot \mathrm{K}\right)$ \\
\hline$I$ & TEG current, A \\
\hline$P_{\text {teg }}$ & TEG power output, $\mathrm{W}$ \\
\hline$Q_{i n}$ & input power, $\mathrm{W} / \mathrm{m}^{2}$ \\
\hline$R_{\text {in }}$ & internal resistance, $\Omega$ \\
\hline$R_{L}$ & load resistance, $\Omega$ \\
\hline $\mathrm{T}$ & temperature, $\mathrm{K}$ \\
\hline$v$ & wind speed, $\mathrm{m} / \mathrm{s}$ \\
\hline$V_{L}$ & load voltage, $\mathrm{V}$ \\
\hline$V_{o c}$ & open circuit voltage, $\mathrm{V}$ \\
\hline $\mathrm{Z}$ & figure of merit, $1 / \mathrm{K}$ \\
\hline Z & figure of merit, $\mathrm{K}^{-1}$ \\
\hline
\end{tabular}

\section{Greek symbols}

\section{Greek symbols}

\begin{tabular}{l}
$\alpha$ \\
$\alpha_{s}$ \\
\hline$\eta_{s t e g}$ \\
\hline$\sigma$ \\
$\kappa$ \\
$\rho$
\end{tabular}

seebeck coefficient, V/K

SSA absorptivity

STEG efficiency

electrical conductivity, S/m

thermal conductivity, $\mathrm{W} / \mathrm{m} / \mathrm{K}$

density, $\mathrm{Kg} / \mathrm{m}^{3}$

\section{Abbreviations}

Abbreviations

$\begin{array}{ll}\mathrm{Bi}_{2} \mathrm{Te}_{3} & \text { Bismuth telluride } \\ \mathrm{PbTe} & \text { lead telluride } \\ \mathrm{PCM} & \text { phase change material } \\ \mathrm{SSA} & \text { solar selective absorber }\end{array}$




\section{Subscripts}

\section{Subscripts}

a

ambient

sky

sky

\section{Introduction}

The need for alternative energy sources has never been more obvious due to the numerous environmental issues like global warming, pollution etc. caused by the use of conventional energy sources such as fossil fuel $[1,2]$. Although, fossil fuel currently supplies $80 \%$ of the world's energy due to the high initial cost of renewable energy systems, the exponential rate at which the world's population is growing and increased energy demand means energy sources like fossil fuel will be eventually exhausted soon [3,4]. Harvesting residual energy is very relevant because it is an alternative source that main depends on thermal losses. In fact, since waste heat will always be released to the environment, it is imperative to develop technologies that can utilize such heat and convert it into useful forms like electricity [5]. For example, about two third of the input energy of internal combustion engine is wasted through exhaust gas and cooling water of engine [6]. If the waste heat can be recovered, a significant amount of fuel can be saved, and cost will be reduced.

A thermoelectric (TE) module is a bi-directional device which can be used to convert heat into electricity and vice-versa depending on the mode of operation [7]. When the TE module is used to convert heat to electricity, it operates on Seebeck effect therefore it is referred to as a thermoelectric generator (TEG) whereas, Peltier effect enables the TE module to function as a thermoelectric cooler (TEC) [8]. Compared to other waste heat recovery technologies, the use of TEG in a waste heat recovery system is advantages due to the following reasons; silent operation, small size, high reliability, no moving part and reduced maintenance required $[9,10]$. However, the low conversion efficiency and power output of the TEG is preventing its widespread application $[11,12]$. Consequently, research on TEG efficiency enhancement is currently a hot field. The use of solar concentrators to increase the input energy incident on the thermoelectric generator is an effective technique to enhance its conversion efficiency. This is because, in theory, an increased temperature difference between the TEG hot and cold ends can enhance the efficiency and power output of the TEG [13]. However, appropriate thermoelectric material must be used with consideration for its maximum operation temperature [14]. When solar radiation is used as the heat source on a thermoelectric generator with solar concentrator, it is referred to as a solar thermoelectric generator (STEG) [15]. Geometry and material optimization are well-researched ways to improve the performance of thermoelectric generators [16]. Current commercially available thermoelectric materials have a figure of merit (ZT) of about 1 therefore, material optimization is very important as a higher figure of merit directly leads to a higher thermoelectric conversion efficiency [17]. On the other hand, geometry optimization is equally important as it can save quantity of thermoelectric material needed and thus, reduce system cost $[18,19]$. 
Pereira et al. [20] studied a concentrated solar thermoelectric generator and a comparison was made between the experimental and numerical results, which showed good agreement. Experimental tests with a high temperature difference of $400{ }^{\circ} \mathrm{C}$ across the hot and cold surfaces of the STEG resulted in a power output of $500 \mathrm{~mW}$ and system efficiency of 1.6\%. Similarly, Sun et al. [21] presented an experimental and numerical investigation of a solar thermoelectric generator. A real-time simulation model of a practical flat-plate STEG was validated with experimental results and an agreement was observed between both results. The results showed that impedance matching between the TEG and external load is very important to obtaining maximum power output from the STEG. Furthermore, Mahmoudinezhad et al. [22] experimentally and numerically investigated the transient response of an oxide solar thermoelectric generator to variable solar radiation. In addition, the effect of incorporating a self-adhesive graphite sheet to the hot surface of the STEG was studied and finite volume method was used to perform the numerical simulation. Results showed that the graphite absorber substantially influenced the power output of the solar thermoelectric generator by enhancing the absorbed radiation. Kossyvakis et al. [23] compared the performance of a solar thermoelectric generator using two configurations including thermal and optical concentration. A numerical study was performed using finite element analysis and a maximum power output of $33.7 \mathrm{~W}$ was obtained using the optical concentration configuration. However, the authors argued that the use of thermal concentration resulted in a higher efficiency compared to the optical concentration.

Similarly, Liu et al. [24] developed a numerical model for a flat-plate solar thermoelectric generator for space applications using two different thermoelectric materials including Bismuth telluride $\left(\mathrm{Bi}_{2} \mathrm{Te}_{3}\right)$ and Lead telluride $(\mathrm{PbTe})$. The influence of thermal concentration ratio, thermoelectric leg length and other geometrical factors on the STEG performance were studied and results showed that device geometry optimization enable the achievement of relatively stable STEG conversion efficiency under high solar radiation intensity. Furthermore, results showed that the maximum conversion efficiency of the STEG was 5.5\% for the $\mathrm{Bi}_{2} \mathrm{Te}_{3}$ based solar thermoelectric generator. Jung et al. [25] presented a wearable solar thermoelectric generator with high temperature difference using a local solar absorber and thermoelectric legs on a polyimide substrate. Using a wearable STEG with 10 pairs of p-n thermoelectric legs, an open circuit voltage of $55.15 \mathrm{mV}$ and power output of $4.44 \mu \mathrm{W}$ was obtained at a temperature difference of $20.9{ }^{\circ} \mathrm{C}$. Liu et al. [26] proposed a novel solar thermoelectric generator with combined segmented thermoelectric materials and asymmetrical legs. Results showed that the new optimized segmented design provided a $14.9 \%$ power output increase compared to non-segmented design. Li et al. [27] investigated a high performance STEG combined with solar concentrators and carbon nanotubes absorber. Results showed that the new system design achieved a peak efficiency of $4.3 \%$ at solar concentration of 78 , and a maximum power output of $11.2 \mathrm{~W}$ at 106-fold suns. Recently, Lv et al. [28] performed an experimental study on a hybrid solar thermoelectric generator composed of heat pipe evacuated tubular collector, solar selective absorber (SSA) and thermoelectric modules. Results showed that the new system design achieved a peak electrical efficiency of $5.2 \%$ and peak exergy efficiency of $7.17 \%$.

Considering the non-uniform heat flux at the TEG surface, Admasu et al. [29] presented a numerical study using finite element based software and an experimental study. The effect of temperature non-uniformity over the heat spreader on the TEG power output was studied and a comparison was made between the TEG power output with uniform temperature distribution and that with non-uniform temperature distribution. Results 
showed that the TEG provides a better power output with uniform temperature distribution over the heat spreader than when no-uniform temperature distribution is present. Ming et al. [30] numerical examined the influence of non-uniform high heat flux on the mechanical performance of a thermoelectric generator. Fresnel lens was as the solar concentrator and the numerical study was carried out using finite element method. Results showed that the non-uniform heat flux on the hot surface of the TEG significantly affects the thermal stress developed in the device and its life expectancy. Furthermore, Yin et al. [31] performed a numerical investigation of a solar thermoelectric generator under non-uniform illumination. Two-dimensional Gaussian distribution was used to modify the illumination profiles incident on the STEG. Fresnel lens was used as the solar concentrator and six non-uniformities of solar illumination were investigated at a constant total energy. Results showed that the power output of the STEG decreased by $1.4 \%$ under non-uniform illumination. He et al. [32] experimentally and numerically studied the effect of non-uniform input heat flux on the performance of a thermoelectric generator array connected in series and parallel. Results indicated that the maximum power output of the TEG connected in series and parallel is only different under non-uniform heat flux.

Phase change material (PCM) have been incorporated into thermoelectric generators due to their unique ability to store thermal energy and regulate temperature. Jaworski et al. [33] presented an experimental study of a thermoelectric generator with PCM as the cooling medium. Results showed that PCM is effective as a heat sink for stabilizing the cold side temperature of the thermoelectric generator. Tu et al. [34] presented a novel thermoelectric generator with phase change material for space application. The numerical simulation and experimental study revealed that the use of paraffin $/ 5 \mathrm{wt} \%$ expanded graphite PCM enhanced the total energy output of the TEG by $32.32 \%$ compared to the TEG with pure paraffin PCM. Similarly, Zhu et al. [35] performed a multi-parameter optimization of a thermoelectric generator integrated with phase change material for space application. Results from the transient thermal study showed that choosing PCM with a suitable melting temperature is an effective method to enhance the overall power output of the TEG. Furthermore, Atouei et al. [36] presented a novel prototype of a two-stage thermoelectric generator integrated with PCM. The experimental results revealed that the proposed design provided an electrical potential increase of $27 \%$ compared to the one-stage TEG. Recently, Lee et al. [37] performed an experimental study of a flexible TEG with flexible heatsink based on PCM for wearable applications. The authors argued that the PCM-based flexible heatsink was smaller and lighter than the conventional metal heatsink. In addition, the power output of the flexible TEG was maintained at around $20 \mu \mathrm{W} / \mathrm{cm}^{2}$ for $33 \mathrm{~min}$ because of the PCM heat sink. Another experimental study on a TEG with PCM was carried out by Atouei et al. [38]. The effect of placing PCM at different locations in the TEG was studied and compared with a conventional TEG without PCM. Results showed that using the PCM at the hot side of the TEG resulted in voltage generation for a longer time even after removing the external heat source and it also protected the module from failure due to high input power.

The literature review above shows that the use of PCM in a TEG is advantageous and solar thermoelectric generators provide enhanced performance. In addition, the harmful effects of non-uniform heat flux on the TEG performance has been shown. Almost all the reviewed papers used the PCM has a heat sink to regulate the cold side temperature. In addition, most numerical studies carried out on STEG currently available in literature assume uniform illumination from solar concentrators. Furthermore, actual heat flux from real solar concentrators have not been applied to TEG, rather, assumed heat flux distributions using Gaussian distribution have been applied. Actual operation of a solar thermoelectric generator is under transient 
conditions, which cause fluctuations of the heat input. Therefore, in this study, for the first time, phase change material is applied at the top surface of the solar thermoelectric generator to unify the incident non-uniform heat flux from an actual compound parabolic concentrator (CPC) and to stabilize the power output from the STEG by significantly reducing the input heat flux fluctuations. A comparison between the STEG with PCM and that without PCM is made under transient and non-uniform heat flux using three-dimensional finite element method. The numerical investigation is carried out using COMSOL 5.4 Multiphysics software and Lighttools software is used for the ray tracing simulation to obtain the heat flux distribution from the compound parabolic concentrator. A transient study is carried out and the electrical performance of the solar thermoelectric generator is investigated. The remaining part of this paper is arranged as follows: structure description and material selection is presented in Section 2, numerical model is presented in Section 3, results and discussion appear in Section 4, and the conclusions from this study are shown in Section 5.

\section{Structure description and material selection}

The solar thermoelectric generator considered in this study is shown in Fig. 1 without the solar concentrator. A comparison study between a solar thermoelectric generator with and without phase change material is performed. The STEG with PCM is shown in Fig. 1a while that without PCM is shown in Fig. 1b. In this study, a commercial thermoelectric generator (GM250-71-14-16) consisting of 71 pairs of thermoelectric legs connected in series electrically and thermally in parallel is used. Aluminum oxide is used as the ceramic material, which enhances heat transfer across the TEG and provides electrical insulation. Copper is used as the conducting material and bismuth telluride $\left(\mathrm{Bi}_{2} \mathrm{Te}_{3}\right)$ is the n-type and p-type thermoelectric material. In addition, as shown in Fig. 1a, the PCM is placed in a container made of copper material and copper fins are used to enhance the heat transfer between the container and the PCM. In both Fig. 1a and Fig. 1b, a solar selective absorber (SSA) is assumed to be present at the top surface. The solar concentrator used in this study is a compound parabolic concentrator (CPC) with an average concentration ratio of 6 . The optical simulation is conducted using the software Lighttools. The geometric model of the CPC is built firstly in SolidWorks and then transferred into Lighttools for the ray tracing simulation. To avoid repetition, the detailed simulation parameters and model for the compound parabolic concentrator can be found in our published paper [39]. The flux distribution from the $\mathrm{CPC}$ is shown in Fig. 2 and the geometric parameters utilized for the numerical simulation are shown in Table 1. The distance from along which the average local concentration ratios is plotted is from the left edge of the solar selective absorber for the concentrator. Furthermore, the solar radiation variation under typical partly cloudy weather condition for a period of time in wet season is shown in Fig. 3 [40]. Temperature dependent thermoelectric material properties [41] are used (shown in Fig. 4) and the other material properties used in this study can be found in Table 2. The phase change material used in this study undergoes phase change from solid to liquid by absorbing the incident non-uniform solar radiation from the compound parabolic concentrator. The properties of a PCM including, melting temperature, cost, availability and chemical stability determines its suitability for specific applications. Therefore, the PCM used in this study is chosen based on its melting temperature and the hot side temperature of the thermoelectric generator. Throughout this study, RT25HC is used as the phase change material and its thermophysical properties are listed in Table 3 [42]. The PCM used in this study is a commercially available PCM manufactured by Rubitherm Technologies GmbH. It is a pure PCM that is capable of storing and realizing 
large quantities of thermal energy at a nearly constant temperature. The melting range according to the manufacturer datasheet is between $22{ }^{\circ} \mathrm{C}$-and $26{ }^{\circ} \mathrm{C}$ while its main peak is at $25{ }^{\circ} \mathrm{C}$. Recently, Mankel et al. [43] performed a differential scanning calorimetry (DSC) tests for RT25HC phase change material and the result obtained is shown in Fig. 5. The DSC curve justifies the manufacturer data and it can be seen that the melting interval is $4{ }^{\circ} \mathrm{C}$ or $4 \mathrm{~K}$. The PCM undergoes endothermic reaction at an onset temperature and the phase change from solid to liquid begins gradually. Furthermore, a large quantity of heat energy is absorbed during the phase change process, which is later released at the end of the phase change. In this study, the PCM absorbs the concentrated solar radiation, which raises its temperature, and when the onset temperature is reached, the phase change process begins. During this process, the PCM helps to maintain the temperature on the solar thermoelectric generator at an almost constant value thereby stabilizing the transient and non-uniform radiation, which in turn leads to a more stable power output from the solar thermoelectric generator. Furthermore, even during periods of low solar radiation, the STEG is still able to provide some power output because of the stored heat released from the phase change material. 


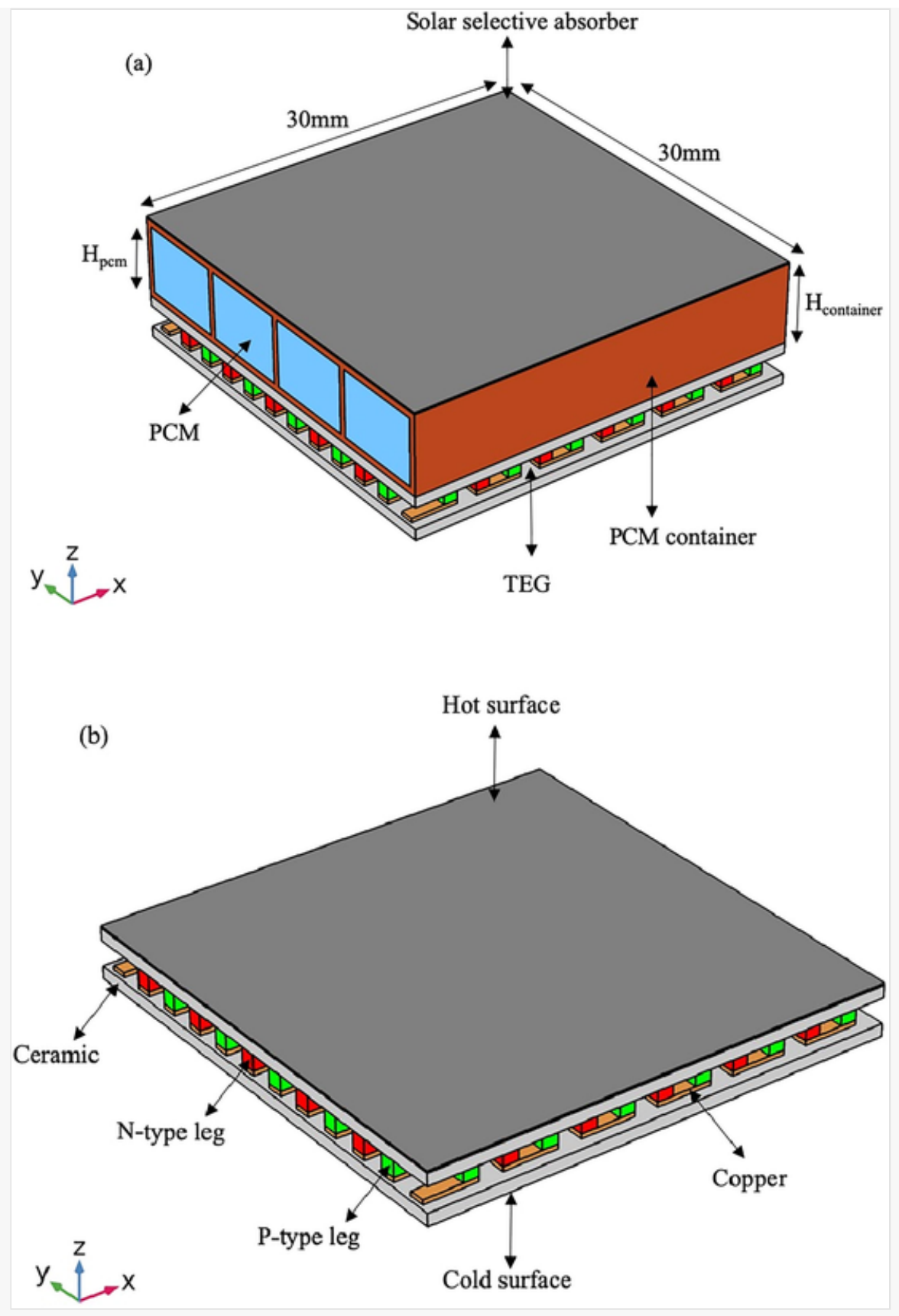

Solar thermoelectric generator (a) with PCM and (b) without PCM. 


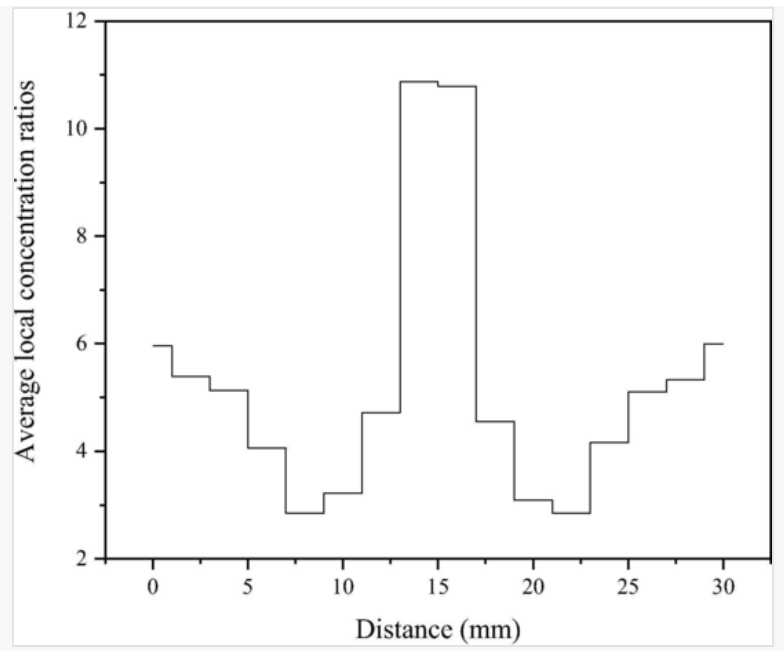

Compound parabolic concentrator flux distribution.

Table 1

(i) The table layout displayed in this section is not how it will appear in the final version. The representation below is solely purposed for providing corrections to the table. To preview the actual presentation of the table, please view the Proof.

Geometric parameters $[9,31,41]$.

\begin{tabular}{|l|l|}
\hline Parameter & Value \\
\hline Ceramic height & $0.8 \mathrm{~mm}$ \\
\hline Copper height & $1 \mathrm{~mm}$ \\
\hline Leg height & $30 \mathrm{~mm}$ \\
\hline Ceramic depth & $30 \mathrm{~mm}$ \\
\hline Ceramic width & $1 \mathrm{~mm}$ \\
\hline Leg width & $1 \mathrm{~mm}$ \\
\hline Leg depth & $6 \mathrm{~mm}$ \\
\hline PCM container height & $5 \mathrm{~mm}$ \\
\hline PCM height & $0.5 \mathrm{~mm}$ \\
\hline PCM fin width & \\
\hline
\end{tabular}




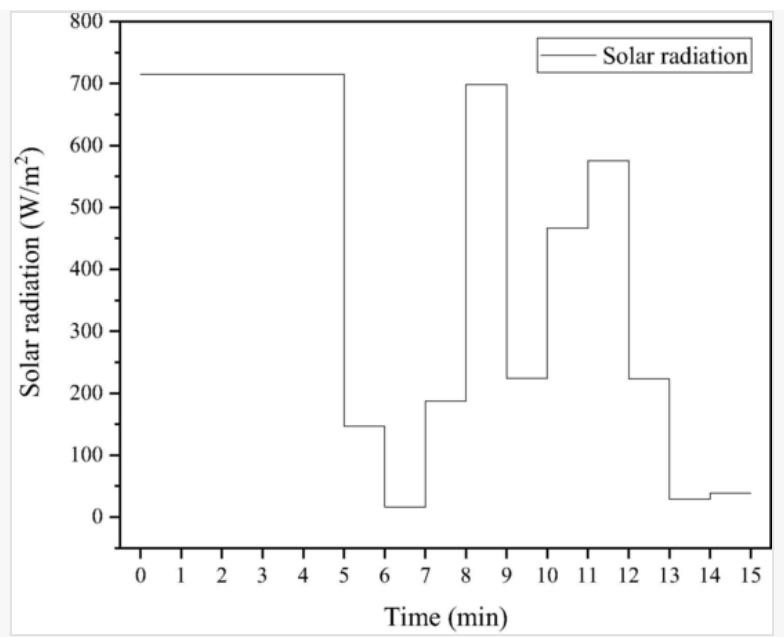

Variation of solar radiation with time [40].

\section{Fig. 4}

(a)

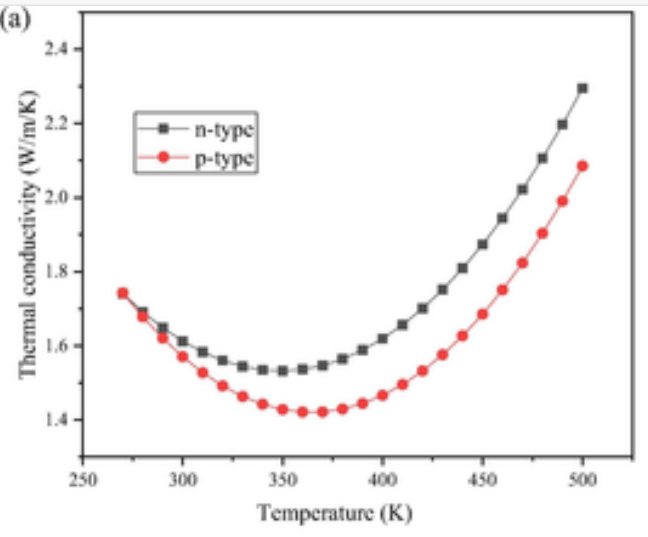

(b)

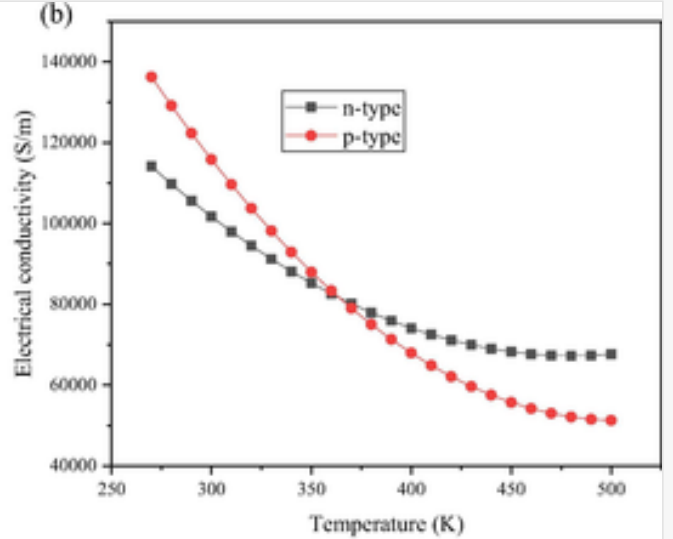

(c)

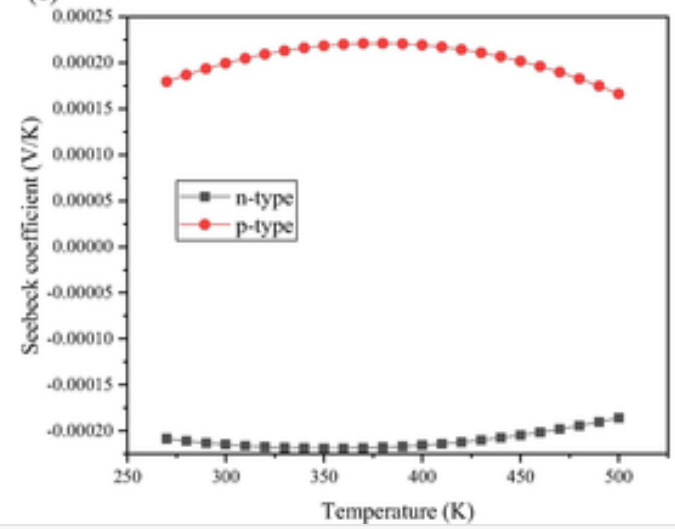

$\mathrm{Bi}_{2} \mathrm{Te}_{3}$ material properties (a) thermal conductivity (b) electrical conductivity and (c) Seebeck coefficient [41]. 
Other material properties used in simulation [31].

\begin{tabular}{|c|c|c|c|c|c|c|}
\hline & $\begin{array}{l}\text { Heat capacity, } \\
C_{p}[\mathrm{~J} /(\operatorname{kgK})]\end{array}$ & $\begin{array}{l}\text { Density, } \rho \\
{\left[\mathrm{kg} / \mathrm{m}^{3}\right]}\end{array}$ & $\begin{array}{l}\text { Seebeck } \\
\text { coefficient, } \alpha \\
{[\mathrm{V} / \mathrm{K}]}\end{array}$ & $\begin{array}{l}\text { Electrical } \\
\text { conductivity, } \sigma \\
{[\mathrm{S} / \mathrm{m}]}\end{array}$ & $\begin{array}{l}\text { Thermal conductivity, } \\
k[\mathrm{~W} /(\mathrm{mK})]\end{array}$ & Emissivity \\
\hline Ceramic & 850 & 3960 & - & - & 18 & 0.9 \\
\hline $\mathrm{Bi}_{2} \mathrm{Te}_{3}$ & 154 & 7700 & $\pm \alpha(T)$ Fig. $4 \mathrm{c}$ & $\sigma(T)$ Fig. 4b & $k(T)$ Fig. $4 \mathrm{a}$ & - \\
\hline Copper & 385 & 8960 & - & $5.998 \times 10^{7}$ & 400 & - \\
\hline SSA & - & - & - & - & - & 0.05 \\
\hline
\end{tabular}

Table 3

(i) The table layout displayed in this section is not how it will appear in the final version. The representation below is solely purposed for providing corrections to the table. To preview the actual presentation of the table, please view the Proof.

Properties of RT25HC phase change material [42].

\begin{tabular}{|l|l|l|}
\hline Properties & \multicolumn{2}{|l|}{ RT25HC } \\
\hline Melting area $\left({ }^{\circ} \mathrm{C}\right)$ & $22-26$ & \\
\hline Peak melting point $\left({ }^{\circ} \mathrm{C}\right)$ & 25 & \\
\hline Congealing area $\left({ }^{\circ} \mathrm{C}\right)$ & $26-22$ & \\
\hline Heat storage capacity $(\mathrm{kJ} / \mathrm{kg})$ & 230 & \\
\hline Specific heat capacity $(\mathrm{kJ} / \mathrm{kg} / \mathrm{K})$ & 2 & Solid \\
\hline & & 0.2 \\
\hline Thermal conductivity $(\mathrm{W} / \mathrm{m} / \mathrm{K})$ & Liquid & 880 \\
\hline Density $\left(\mathrm{kg} / \mathrm{m}^{3}\right)$ & 0.2 & \\
\hline
\end{tabular}




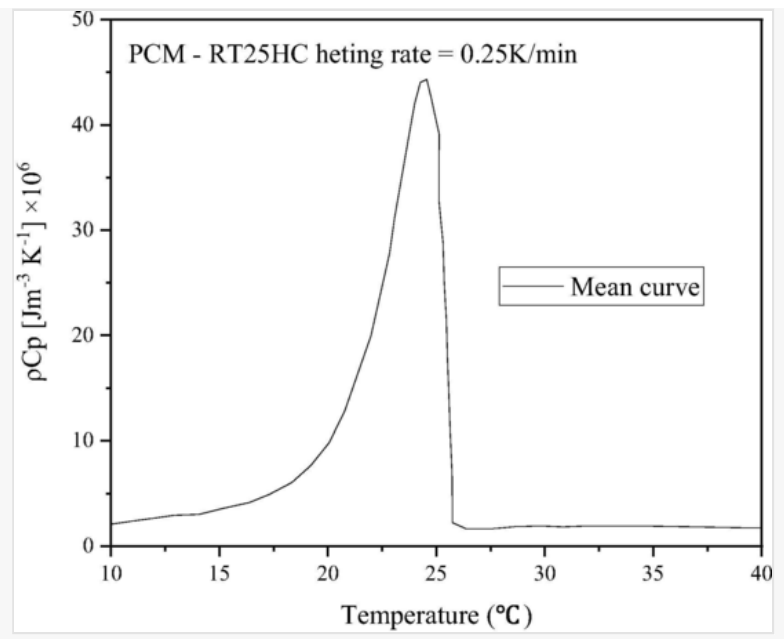

DSC curve of RT25HC PCM [43].

\section{Numerical model}

The performance of the thermoelectric generator and phase change material are described using the equations below.

\subsection{Thermoelectric generator}

The governing equations describing the TEG performance are given as [44]:

$$
\rho C_{p} \frac{\partial T}{\partial t}+\nabla \cdot \vec{q}=\dot{q}
$$

where $C_{p}$ represents the specific heat capacity, $T$ is the temperature, $\rho$ represents the density, $\vec{q}$ is the heat flux vector and $\dot{q}$ represents the heat generation rate per unit volume.

The equation for the electric charge continuity is expressed as [45],

$$
\nabla \cdot\left(\vec{J}+\frac{\partial \vec{D}}{\partial t}\right)=0
$$

where $\vec{J}$ represents the electric current density vector and $\vec{D}$ signifies the electric flux density vector.

The equations below are used to couple Eqs. (1) and (2) [46],

$$
\vec{q}=T[\alpha] \cdot \vec{J}-[\kappa] \cdot \nabla T
$$


where $[\alpha]$ represents the Seebeck coefficient matrix, $[\kappa]$ represents the thermal conductivity matrix and $[\sigma]$ is the electrical conductivity matrix.

$$
\vec{E}=-\nabla \varphi
$$

where $\vec{E}$ represents the electric field intensity vector and $\varphi$ is the electric scalar potential.

Combination of the above equations results in the coupled thermoelectric equations,

$$
\rho C_{p} \frac{\partial T}{\partial t}+\nabla \cdot(T[\alpha] \cdot \vec{J})-\nabla \cdot([\kappa] \cdot \nabla T)=\dot{q}
$$

$$
\nabla \cdot\left([\varepsilon] \cdot \nabla \frac{\partial \varphi}{\partial t}\right)+\nabla \cdot([\sigma] \cdot[\alpha] \cdot \nabla T)+\nabla \cdot([\sigma] \cdot \nabla \varphi)=0
$$

where $[\varepsilon]$ represents the dielectric permittivity matrix.

Finally, the coupled thermoelectric governing equations can rewritten as [47],

$$
\nabla \cdot(T \alpha \vec{J})-\nabla \cdot(\kappa \nabla T)=\dot{q}
$$

$$
\nabla \cdot(\sigma \alpha \nabla \mathrm{T})+\nabla \cdot(\sigma \nabla \varphi)=0
$$

The thermoelectric generator electrical performance is described by the equations below [8]:

$$
V_{O C}=\alpha \Delta T
$$

where $V_{O C}$ is the open circuit voltage, $\alpha$ is the Seebeck coefficient and $\Delta T$ is the temperature difference between the hot and cold sides of the TEG. 


$$
V_{L}=V_{O C}-R_{i n} I=R_{L} I
$$

where $R_{\text {in }}$ represents the TEG internal resistance, $V_{L}$ represents the load output voltage, and $I$ presents the current of the TEG which is expressed as,

$$
I=\frac{V_{O C}}{R_{\text {in }}+R_{L}}
$$

The TEG power output is expressed as,

$$
P_{\text {teg }}=V_{L} I=R_{L} I^{2}
$$

$$
\eta_{\text {teg }}=\frac{P_{\text {teg }}}{Q_{\text {in }}}
$$

where $\eta_{\text {teg }}$ represents the efficiency of the TEG and $Q_{i n}$ represents the input power at the TEG top surface.

\subsection{Solar thermoelectric generator}

At the top surface of the STEG, the input power is given as [48]

$$
Q_{\text {in }}=C G A_{s} \alpha_{s} \eta_{\text {opt }}
$$

where $A_{s}$ is the area of solar selective absorber $(30 \mathrm{~mm} \times 30 \mathrm{~mm})$ which is placed on the top surface of the solar thermoelectric generator, $\alpha_{s}$ is the SSA absorptivity $(0.95) \eta_{o p t}$ represents the optical efficiency (0.90) and the SSA emissivity is 0.05 [31]. $C$ represents the concentration ratio which is obtained from compound parabolic concentrator with average local concentration ratios along the x-axis of the STEG shown in Fig. 2. Lastly, $G$ represents the solar radiation, which is shown in Fig. 3.

Heat loss due to radiation and convection at the top surface of the solar TEG with and without PCM are considered in this study. The sky temperature is used for the radiative heat loss calculation and it is given as $[49,50]$,

$$
T_{s k y}=0.0552 T_{a}^{1.5}
$$


where $T_{a}$ is the ambient temperature and $T_{s k y}$ is sky temperature.

Convective heat transfer coefficient is given in terms of wind speed as [51],

$$
h=5.82+4.07 v
$$

where $v$ is the wind speed $(1 \mathrm{~m} / \mathrm{s})$.

The STEG efficiency is given as [44]:

$$
\eta_{S T E G}=\eta_{\text {teg }} \alpha_{s} \eta_{\text {opt }}
$$

\subsection{Phase change material}

The phase change numerical model used in this study is based on the apparent heat capacity method. Initially, the PCM is in solid phase and the conduction equation in solid PCM is given as [52]:

$$
\rho C_{e q} \frac{\partial T}{\partial t}+\nabla \cdot\left(-k_{e q} \nabla T\right)=Q
$$

where $C_{e q}$ is the effective heat capacity and $k_{e q}$ is the effective thermal conductivity.

When the phase change material reaches its phase change temperature i.e. melting temperature $\left(T_{m}\right)$, it is assumed that the phase change process occurs over time period. Consequently, this time interval is defined between $T_{m}-\Delta T / 2$ and $T_{m}+\Delta T / 2$ and the phase of the PCM during this time period is defined by the function, $\theta$. This function, $\theta$ is called the liquid fraction or phase transition function because it presents the fraction of the phase before the phase transition. Furthermore, the phase transition function is equal to 1 before $T_{m}-\Delta T / 2$ (i.e. solid phase) and 0 after $T_{m}+\Delta T / 2$ (i.e. liquid phase). Furthermore, the density, $\rho$ and specific enthalpy, $H$ are given as [53]:

$$
\rho=\theta \rho_{p h 1}+(1-\theta) \rho_{p h 2}
$$

$$
H=\frac{1}{\rho}\left(\theta \rho_{p h 1} H_{p h 1}+(1-\theta) \rho_{p h 2} H_{p h 2}\right)
$$

where $p h 1$ and $p h 2$ represent a material in phase 1 and phase 2 respectively. 
The specific heat capacity is given as [53]:

$$
C_{p}=\frac{1}{\rho}\left(\theta_{1} \rho_{p h 1} C_{p, p h 1}+\theta_{2} \rho_{p h 2} C_{p, p h 2}\right)+\left(H_{p h 2}-H_{p h 1}\right) \frac{d \alpha_{m}}{d T}
$$

where $\theta_{1}=\theta$ and $\theta_{2}=1-\theta$.

The mass fraction $\alpha_{m}$ is given as:

$$
\alpha_{m}=\frac{1}{2} \frac{\theta_{2} \rho_{p h 2}-\theta_{1} \rho_{p h 1}}{\rho}
$$

The specific heat capacity is the sum of an equivalent heat capacity, $C_{e q}$ [53]:

$$
C_{e q}=\frac{1}{\rho}\left(\theta_{1} \rho_{p h 1} C_{p, p h 1}+\theta_{2} \rho_{p h 2} C_{p, p h 2}\right)
$$

The distribution of latent heat $C_{L}$ is given as:

$$
C_{L}(T)=\left(H_{p h 2}-H_{p h 1}\right) \frac{d \alpha_{m}}{d T}
$$

$C_{L}$ is approximated so that the total heat per unit volume released during the phase transformation is equal to the latent heat $L$ :

$$
\int_{T_{m}-\frac{\Delta T}{2}}^{T_{m}+\frac{\Delta T}{2}} C_{L}(T) d T=L \int_{T_{m}-\frac{\Delta T}{2}}^{T_{m}+\frac{\Delta T}{2}} \frac{d \alpha_{m}}{d T} d T=L
$$

In the heat equation, the apparent heat capacity, $C_{p}$ used is given as:

$$
C_{p}=\frac{1}{\rho}\left(\theta_{1} \rho_{p h 1} C_{p, p h 1}+\theta_{2} \rho_{p h 2} C_{p, p h 2}\right)+C_{L}
$$




$$
k_{e q}=\theta_{1} k_{p h 1}+\theta_{2} k_{p h 2}
$$

While the effective density is given as:

$$
\rho=\theta_{1} \rho_{p h 1}+\theta_{2} \rho_{p h 2}
$$

\subsection{Computational procedure and boundary conditions}

This study is conducted using finite element software, COMSOL 5.4 Multiphysics software. The following interfaces are used in the study; heat transfer in solid and liquid, electric current and electric circuit. In-built phase change interface in COMSOL is used under the heat transfer in liquid interface. The material properties for the solid and liquid PCM materials are defined separately and coupled with the phase transition function. In this study, thermal contact resistance is considered between the lower surface of the PCM container and the TEG ceramic top surface. An assumed value of $200 \mathrm{~mm}^{2} \cdot \mathrm{K} / \mathrm{W}$ [54] is used in this study for the thermal contact resistance however, perfect contact is preferable. The boundary conditions used in this study are listed below:

1) Transient conditions are assumed.

2) A constant temperature $\left(20^{\circ} \mathrm{C}\right)$ boundary condition is assumed on the cold surface of the STEG.

3) The copper electrodes on the n-type and p-type legs are connected to the ends of an external load.

4) The external surfaces of the PCM container are insulated.

\subsubsection{Boundary and initial conditions mathematical expression}

1. Initial temperature on all surfaces: $t=0 ; T(x, y, z)=T_{a}=20{ }^{\circ} \mathrm{C}$.

2. Surface-to-ambient radiation at top surface of SSA: $-\boldsymbol{n} \cdot \boldsymbol{q}=\varepsilon \sigma\left(T_{s k y}^{4}-T_{s s a}^{4}\right)$. Where $\varepsilon$ is SSA emissivity, $\sigma$ is Stefan-Boltzmann constant $\left(5.670367 \times 10^{-8} \mathrm{~W} / \mathrm{m}^{2} \cdot \mathrm{K}^{4}\right)$ and $T_{\text {ssa }}$ is temperature of SSA top surface.

3. Convective heat loss at SSA top surface: $-\boldsymbol{n} \cdot \boldsymbol{q}=h\left(T_{a}-T_{s s a}\right)$.

4. Cold side temperature of STEG: $T_{c}=20^{\circ} \mathrm{C}$.

5. Initial thermoelectric electric potential: $V=0$.

6. Insulation on all other boundaries: $-\boldsymbol{n} \cdot \boldsymbol{q}=0$. Where $\boldsymbol{n}$ the boundary normal vector and $\boldsymbol{q}$ is heat flux vector. 


\subsection{Model validation}

Firstly, the accuracy of the model is tested by performing a mesh convergence test. This test ensures that the results obtained from this numerical study are independent of the mesh size. Therefore, in-built COMSOL Multiphysics mesh settings are used and five different mesh element size are tested. The results obtained are shown in Table 4 including the maximum power output and the maximum temperature for the solar thermoelectric generator with phase change material. It can be seen from Table 4 that the results obtained for the different mesh element size are similar although convergence is achieved at the Normal mesh is used. Consequently, throughout this study, Fine mesh is used to ensure increased accuracy of the numerical model and results obtained.

Table 4

(i) The table layout displayed in this section is not how it will appear in the final version. The representation below is solely purposed for providing corrections to the table. To preview the actual presentation of the table, please view the Proof.

Mesh convergence test.

\begin{tabular}{|l|l|l|l|}
\hline Number of domain elements & Element size & Maximum power output $(\mathbf{m W})$ & Maximum temperature $\left({ }^{\circ} \mathbf{C}\right)$ \\
\hline 8652 & Extremely coarse & 5.44 & 27.131 \\
\hline 17,285 & Extra coarse & 5.75 & 27.40 \\
\hline 34,823 & Coarser & 5.61 & 27.21 \\
\hline 104,522 & Normal & 5.25 & 27.13 \\
\hline 156,960 & Fine & 5.25 & 27.13 \\
\hline
\end{tabular}

Secondly, this numerical study is about the integration of phase change material and thermoelectric device therefore, the model used is validated with a similar thermoelectric-phase change model used in a recently published paper by Manikandan et al. [55]. The objective is to ensure the numerical model is accurate therefore, the material properties and simulation conditions are set to those in the paper [55] and the result obtained is shown in Fig. 6a. Furthermore, a commercial thermoelectric generator (GM250-71-14-16) is used in this study therefore, a full-scale model is built. The datasheet from the manufacturer, which contains the experimental results obtained and the operating parameters of the thermoelectric generator including matched load power output at different hot side temperature, is used to validate the numerical model and the result obtained is shown in Fig. 6b. Considering Fig. 6a and Fig. 6b, it is observed that the present results are in good agreement with the published results consequently, the numerical model used in this study is accurate and justifiable. 

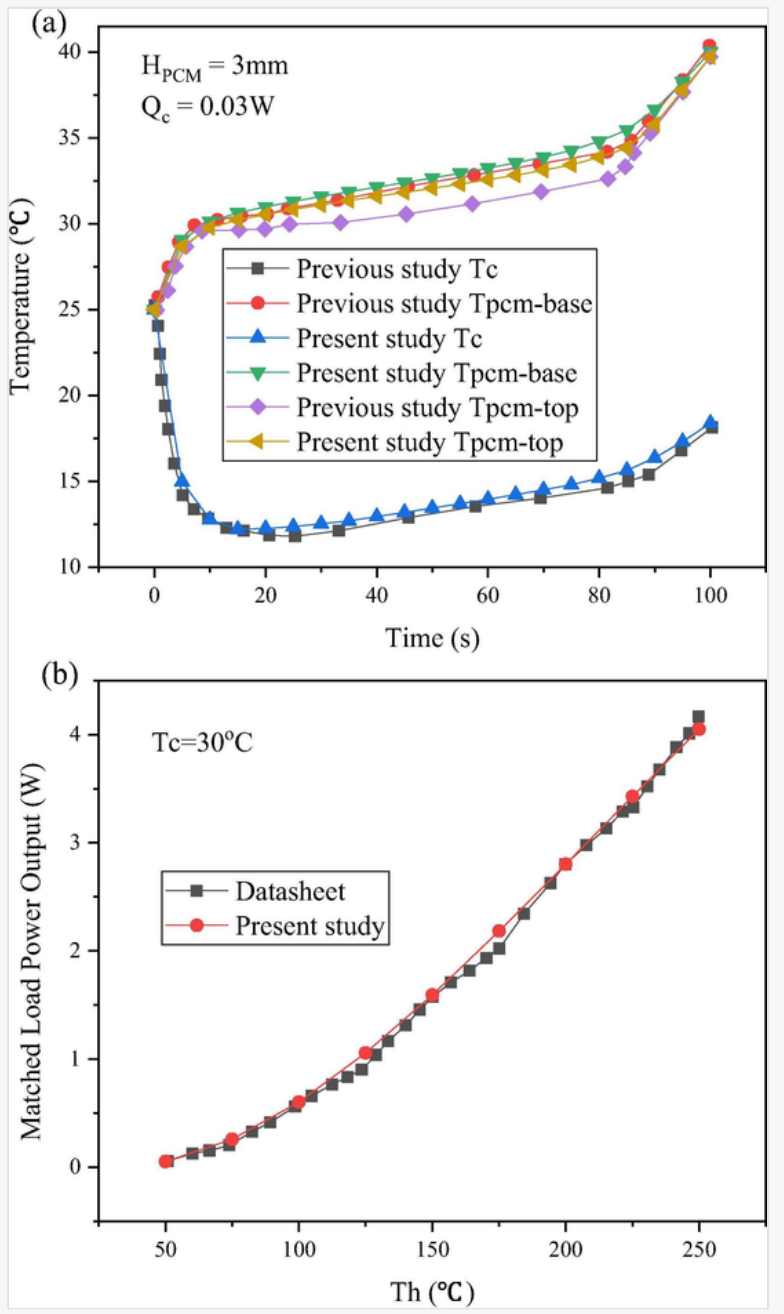

Verification of (a) thermoelectric-PCM model with previous study [55] and (b) TEG module with manufacturer data [41].

\section{Results and discussion}

This section presents the results obtained from the numerical study. Transient simulations are performed for the solar thermoelectric generator with and without phase change material. The CPC flux distribution profile and solar radiation shown in Fig. 2 and Fig. 3 respectively are combined and used for the numerical study. Consequently, each simulation is performed for a period of $15 \mathrm{~min}$.

\subsection{Effect of PCM fin number}

In this study, fins are attached to the PCM container to enhance the heat transfer between the container and the PCM. The variation of the PCM fins with the power output, temperature difference and efficiency of the STEG with PCM for the time period considered is shown in Fig. 7a, Fig. 7b and Fig. 7c respectively. A similar trend is observed in Fig. 7a, Fig. 7b and Fig. 7c due to the solar radiation pattern shown in Fig. 3. Solar radiation is one of the most important parameters that influence the performance of the solar thermoelectric generator. It can be seen from the figures that, peak power output, temperature difference and efficiency of the STEG with 
PCM is achieved after 5 min after which a sharp decline is observed due to the drastic reduction in solar radiation. Furthermore, because the solar radiation at the initial time is high and is maintained for $5 \mathrm{~min}$, the STEG with PCM quickly responds therefore, it takes just $1 \mathrm{~min}$ for the power output, temperature difference and efficiency shown in Fig. 7a, Fig. 7b and Fig. 7c respectively, to significantly increase from the initial zero value. However, although the solar radiation is constant for the first $5 \mathrm{~min}$, the power output, temperature difference and efficiency of the STEG are not constant but rather, increase gradually due to the presence of the PCM on the top surface. During the first $5 \mathrm{~min}$, the PCM receives the concentrated solar radiation and when its melting temperature is attained, it gradually begins to melt and this is the reason for the gradual increase observed between $1 \mathrm{~min}$ and 5 min in Fig. 7a, Fig. 7b and Fig. 7c.

\section{Fig. 7}
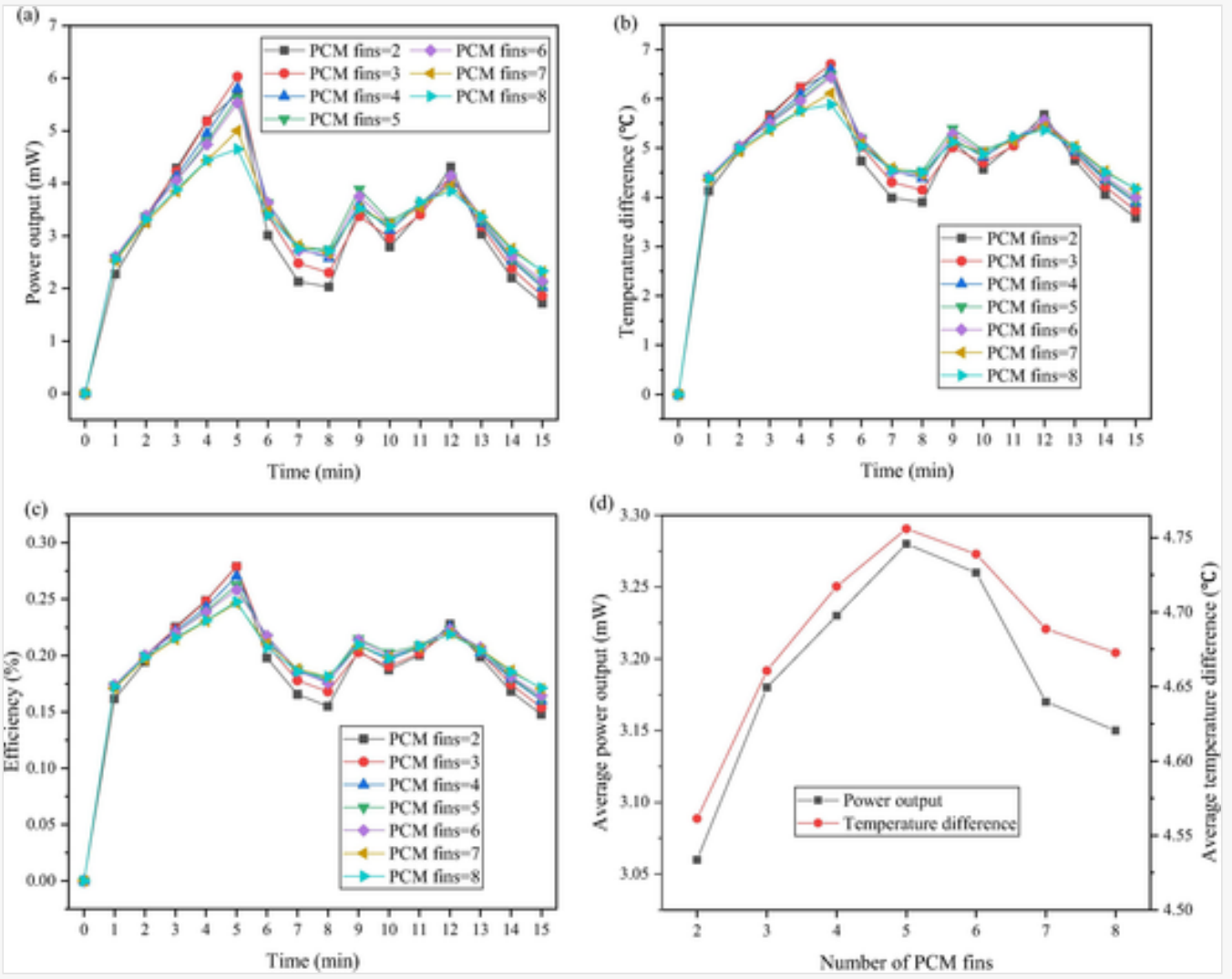

Number of PCM fins variation with (a) power output (b) temperature difference (c) efficiency and (d) average power output and average temperature difference.

For the sake of PCM fin number selection, the average values for the power output and temperature difference across the STEG over a period of $15 \mathrm{~min}$ is considered as shown in Fig. 7d. This provides a clearer understanding of the effect of number of PCM fins on the performance of the solar thermoelectric generator. It can be seen clearly from Fig. $7 d$ that the highest values for average power output and average temperature difference are obtained at fin number 5. Furthermore, a gradual increase is observed initially as the PCM fin number is increased before it sharply declines thereby showing the important of fin optimization. The average power output of the STEG with PCM increased by 7.19\% when the fin number increased from 2 to 5 while it 
decreased by $3.96 \%$ when the fin number increased from 5 to 8 . Similarly, the average temperature difference across the hot and cold sides of the STEG increased by $4.26 \%$ when the fin number increased from 2 to 5 whereas it decreased by $1.75 \%$ when the fin number increased from 5 to 8 . Consequently, it is obvious that proper selection of PCM fin number could enhance the performance of the STEG with PCM. Therefore, throughout this study, a fin number of 5 (shown in Fig. 1a) is used. Since the actual concentrated solar radiation is incident on the PCM container, the fin optimization is important to enhance the heat transfer from the container to the PCM and subsequently to the STEG.

\subsection{Effect of PCM height}

The height of the PCM on the solar thermoelectric generator could affect its performance therefore; the effect of different PCM height on the STEG performance is shown in Fig. 8. The variation of the PCM height with the power output, temperature difference and efficiency of the STEG with PCM for the time period considered is shown in Fig. 8a, Fig. 8b and Fig. 8c respectively. It is very clear from Fig. 8a, Fig. 8b and Fig. 8c that the power output, temperature difference and efficiency of the STEG respectively decrease as the PCM height is increased. Furthermore, it is clear that peak performance is obtained after 5 min due to the solar radiation pattern. From Fig. 8a, Fig. 8b and Fig. 8c, it can be seen that the peak power output, temperature difference, and efficiency of the STEG decrease respectively by $52.11 \%, 30.71 \%$ and $32.87 \%$ when the PCM height is increased from $5 \mathrm{~mm}$ to $20 \mathrm{~mm}$. The reason for the decrease in performance of the STEG is the position of the PCM. Unlike the conventional arrangement whereby the PCM is used as the heat sink, in this study, the preference is to reduce the temperature fluctuations due to the transient solar radiation and to unify the nonuniform heat flux from the solar concentrators. Therefore, in this study, the PCM is positioned at the top surface of the STEG. Consequently, increase in PCM height, which leads to an increase in volume, simply increase the time required to completely melt the PCM. 

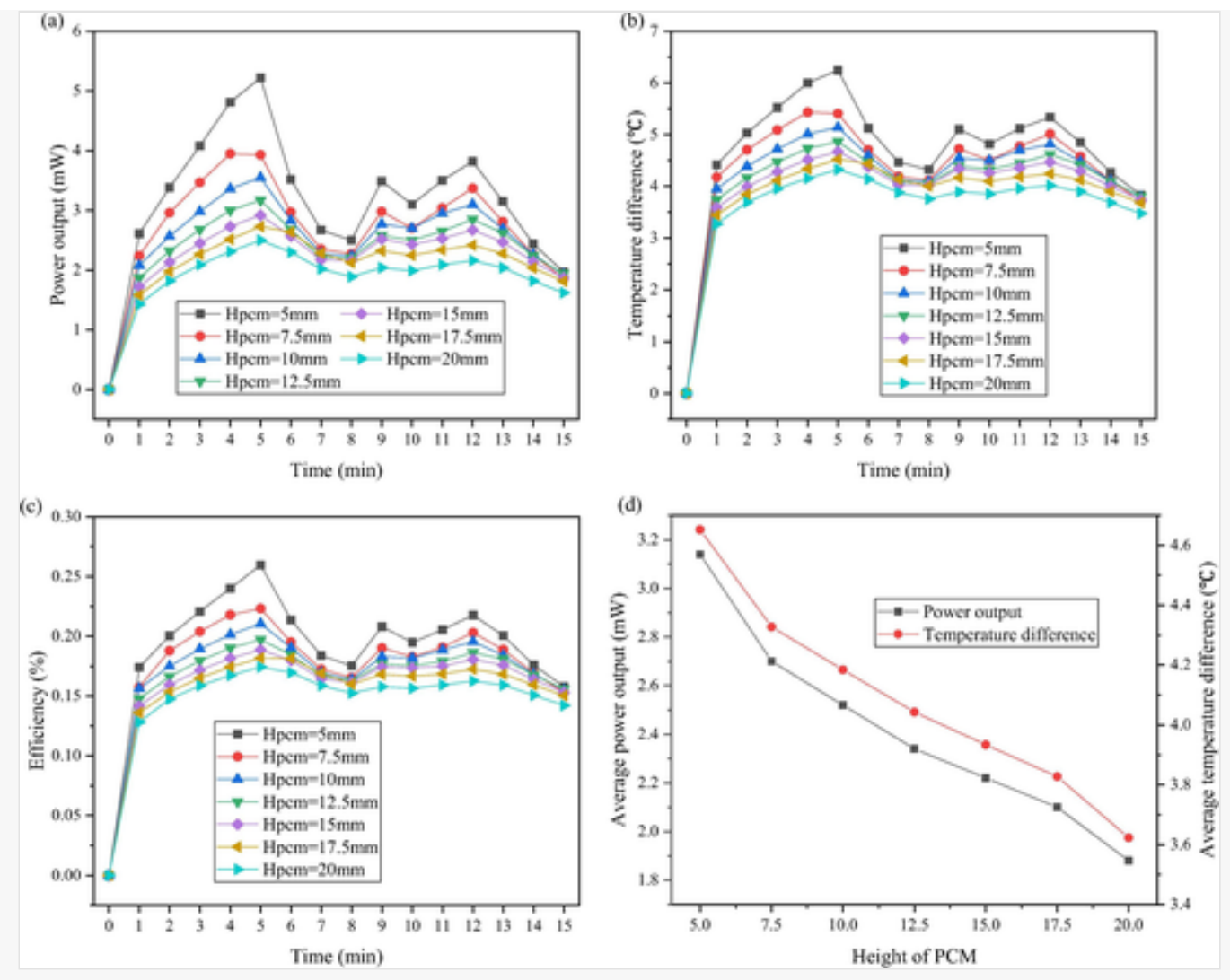

Height of PCM variation with (a) power output (b) temperature difference (c) efficiency and (d) average power output and average temperature difference.

Since the area of the PCM is constant, an increase in height corresponds to an increase in volume of the PCM. Furthermore, if a small PCM height is used such as $5 \mathrm{~mm}$, the PCM can melt quicker and the corresponding increase in temperature will enhance the performance of the STEG by increasing the temperature difference across it. Consequently, the PCM in this study is performing a dual function of stabilizing and unifying the transient non-uniform heat flux from the solar concentrator, and increasing the temperature difference across the STEG when it melts. However, it can also be seen from Fig. 8a, Fig. 8b and Fig. 8c that the increase in PCM height provides a more stable performance in terms of power output, temperature difference and efficiency respectively. The reason for this is because, the increase in PCM height leads to an increase in the time required to melt the phase change material. Furthermore, the average power output and average temperature difference across the STEG is shown in Fig. 8d for different PCM height. A decreasing trend is observed from Fig. 8d because of the reasons explained above. The average power output and average temperature difference across the STEG decrease by $40.13 \%$ and $22.13 \%$ respectively when the PCM height is increased from $5 \mathrm{~mm}$ to $20 \mathrm{~mm}$. Consequently, a PCM height of $5 \mathrm{~mm}$ is used for the remainder of this study.

\subsection{Effect of PCM and thick copper plate}

In this section, the significance of using phase change material at the top surface of the STEG is presented and a comparison is made with a STEG, which has a thick copper plate $(5 \mathrm{~mm})$ at the top surface instead of PCM. In addition, the two systems are compared with a solar thermoelectric generator without PCM or thick copper plate at the top surface. The variation of the power output obtained from the three systems studied with time is 
shown in Fig. 9a. Since the solar radiation at the initial time is high and maintained at a constant value for 5 min, the STEG without PCM and thick copper plate responds the quickest followed by the STEG with copper plate while the STEG with PCM provides the lowest responds. In addition, it can be seen from Fig. 9a that the power output of the STEG without PCM varies significantly with time because of the solar radiation pattern. This kind of unstable power output with very high peaks and low values could significantly affect the performance and life span of the device being powered. For several applications in which the solar thermoelectric generator could be useful, stable power output is required and beneficial. This is specifically why the use of PCM at the top surface of the STEG is important. As shown in Fig. 9a, the power output of the STEG with PCM RT25HC graduate increases with time after which it stabilizes. Although the STEG with PCM cannot provide the peak power outputs provided by the solar thermoelectric generator without phase change material, it is still very useful for providing a stable power output, which is more important for specific applications and under transient conditions.

\section{Fig. 9}
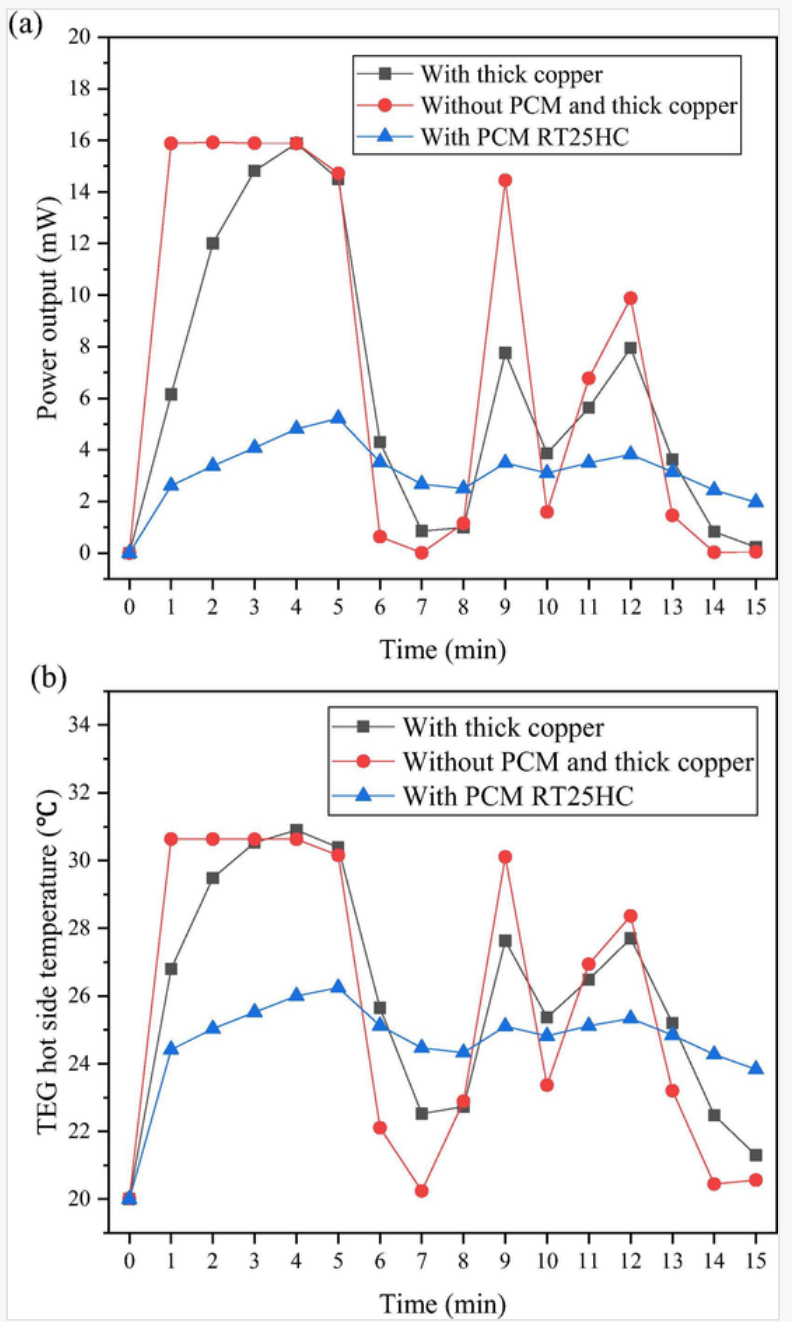

Variation of time with (a) power output and (b) temperature difference for STEG with and without PCM. 
Between $1 \mathrm{~min}$ and $15 \mathrm{~min}$, the difference between the maximum and minimum power output of the solar thermoelectric generator without PCM is $15.88 \mathrm{~mW}$ while that of the STEG with thick copper plate is $15.65 \mathrm{~mW}$ and that of the STEG with PCM is $3.25 \mathrm{~mW}$. This is very significant because it shows that the use of phase change material on the solar thermoelectric generator can provide a more stable power output over a long period. In addition, it can be seen from Fig. 9a that the STEG with PCM outperforms the STEG without PCM and that with thick copper plate at very low solar radiation periods such as between 7-min and -8 min and 13-min- 15 min. In fact, after $15 \mathrm{~min}$, the STEG with PCM still provides a power output of $1.97 \mathrm{~mW}$ while the STEG without PCM provides an almost zero $(0.04 \mathrm{~mW})$ power output and the STEG with thick copper plate provides a $0.23 \mathrm{~mW}$ power output, which is significantly lower compared to that of the STEG with PCM. This is one of the advantages of using phase change material because it can help the STEG provide power output during periods of zero or very low solar radiation.

Furthermore, the hot side temperature of the STEG with and without PCM is shown in Fig. 9b. Since the cold side temperature is kept constant, the transient and non-uniform heat flux from the solar concentrator mainly affects the hot side temperature of the solar thermoelectric generator. It is clear from Fig. $9 \mathrm{~b}$ that the hot side temperature of the STEG without PCM is very unstable because of the solar radiation pattern. In addition, Fig. $9 \mathrm{~b}$ shows that after $1 \mathrm{~min}$, the solar thermoelectric generator without PCM quickly attains its highest hot side temperature of $30.63{ }^{\circ} \mathrm{C}$. This could be harmful to the solar thermoelectric generator if very high concentrated solar radiation is used. This is because, each thermoelectric generator has a maximum temperature it can tolerate consequently, this limit could be exceeded which would damage the device. However, using a PCM at the top surface of the STEG would prevent such occurrence from happening as shown in Fig. 9b. Therefore, the results confirm that the phase change material has a great potential for protecting the solar thermoelectric generator when high solar radiation is utilized. In addition, Fig. 9b shows that the use of PCM at the top surface of the STEG could significantly reduce the effect of transient and non-uniform heat flux fluctuations on the STEG temperature. Furthermore, after $15 \mathrm{~min}$, the hot side temperature of the STEG with PCM is greater than that of the STEG without PCM and STEG with thick copper plate by $15.90 \%$ and $11.90 \%$ respectively. Consequently, the PCM can provide the hot side temperature for the STEG during periods of zero or very low solar radiation.

\subsection{Liquid fraction of PCM}

The phase change phenomenon of the PCM from solid to liquid can be better observed by the liquid fraction of the PCM. The liquid fraction is taken as zero during the sensible heating of the PCM in its solid phase while it is taken as one during its liquid phase and it increases from zero to one during the melting phase. The liquid fraction of the PCM with various fin numbers is shown in Fig. 10a. It can be seen that initially, the melting time reduces as the PCM fin number is increased. In addition, it is clear that the highest value of liquid fraction is obtained after 5 min for all fin number considered. This is because of the high concentrated solar radiation value, which is maintained for $5 \mathrm{~min}$. If that high concentrated solar radiation is kept constant for a longer period, the PCM will eventually melt completely and the liquid fraction value will become constant at 1. However, since the radiation varies with time, the PCM does not completely melt. Furthermore, it can be seen from Fig. 10a that it takes just 1 min for the melting temperature of the PCM to be attained at which point the PCM beings to melt and this is why the liquid fraction increased from 0 to 0.1 after $1 \mathrm{~min}$. The reason for this 
is because of the initial high solar radiation, which quickly raises the temperature of the system, and because of the low melting temperature of the PCM. Furthermore, Fig. 10b shows the liquid fraction of the PCM for different PCM height. It is very clear that increase in PCM height leads to a decrease in liquid fraction. This is the reason for the performance results shown in Fig. 8 for the solar thermoelectric generator. Furthermore, the significant difference in power output obtained from the STEG with PCM height of $5 \mathrm{~mm}$ and others shown in Fig. 8a is due to the liquid fraction shown in Fig. 10b. It is clear that a larger percentage of the PCM melts when the PCM height of $5 \mathrm{~mm}$ is used compared to other height values. However, the absorbed solar energy is still not high enough to completely melt the PCM despite the use of solar concentrator because the compound parabolic concentrator considered in this study is a low concentration ratio concentrator.

\section{Fig. 10}
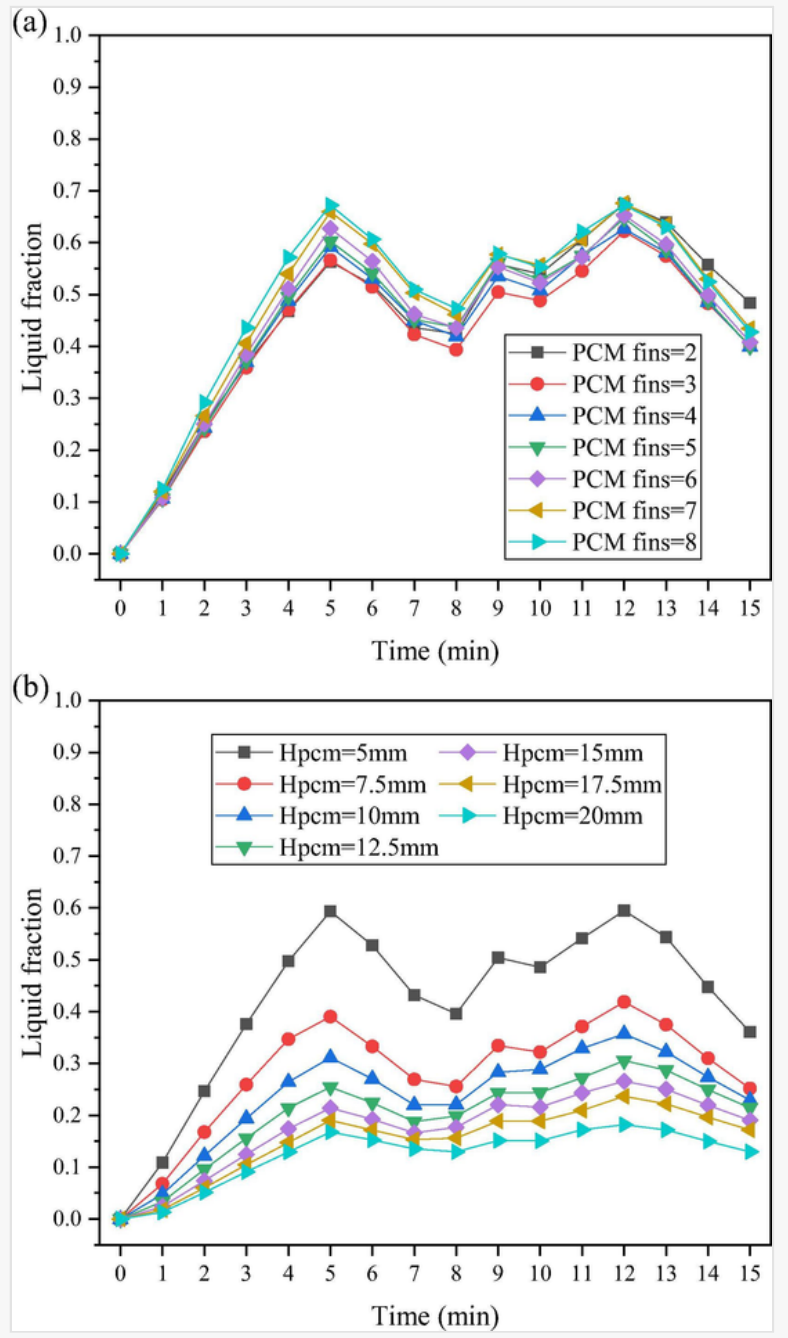

Variation of liquid fraction with time for different (a) PCM fins and (b) PCM height.

\subsection{Temperature distribution and liquid fraction}

To better understand the behavior of the STEG with and without PCM, three-dimensional temperature distribution is presented for both cases. Fig. 11 shows the three-dimensional temperature distribution of the 
STEG without PCM. The effect of the non-uniform heat flux distribution from the compound parabolic concentrator (CPC) used in this study, which is presented in Fig. 2 on the temperature distribution of the STEG without PCM, is shown in Fig. 11. As expected, the middle region of the STEG attains the highest temperature due to the flux distribution being higher in that region as shown in Fig. 2. While Fig. 11a shows the temperature distribution of the STEG without PCM at $5 \mathrm{~min}$, Fig. $11 \mathrm{~b}$ shows the temperature distribution at 15 min. It can be seen that the temperature difference across the STEG without PCM decreased from $11^{\circ} \mathrm{C}$ ( Fig. 11a) to $6.6^{\circ} \mathrm{C}$ (Fig. 11b) due to the decrease in solar radiation. Furthermore, Fig. 11c and Fig. 11d show the actual temperature distribution at the top surface of the thermoelectric legs. The non-uniform heat flux from the solar concentrator affects the temperature distribution on the thermoelectric legs as shown in Fig. 11c and Fig. 11d at 5 min and 15 min respectively. In addition, it can be seen from Fig. 11c and Fig. 11d that the highest temperature is in the middle thermoelectric legs.

\section{Fig. 11}

Time=5 min Volume: Temperature $(\mathrm{deg})$

(a)

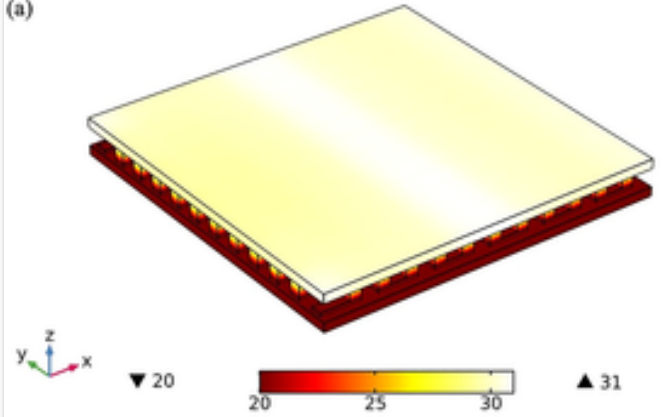

Time= 5 min

(c)
Volume: Temperature (degc) ロロロロロロロロロロロ

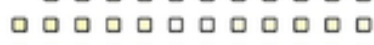

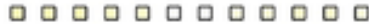

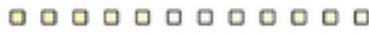
믐ㅁㅁㄷㅁㅁำ

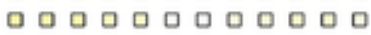
뭄ㅁㅁㅁำ

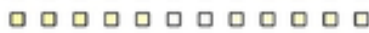

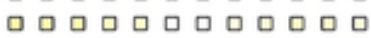

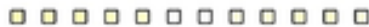
ด ดם

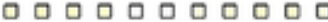
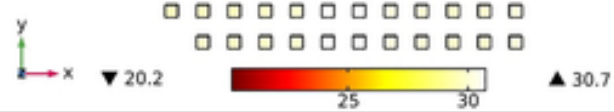

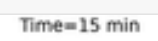

(b)

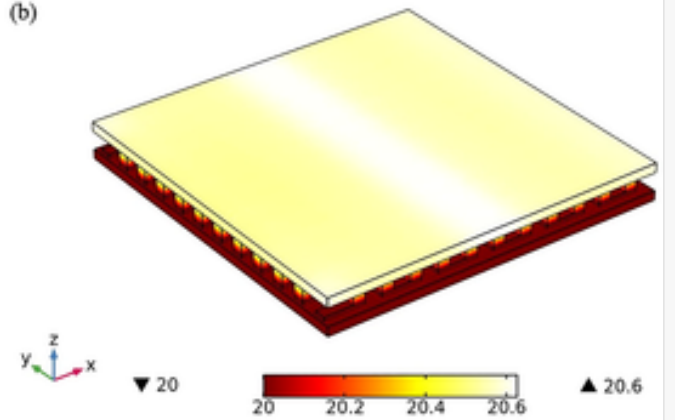

Time $=15 \mathrm{~min}$

(d)
Volume: Temperature (degC) ロロロロロロロロロロロ

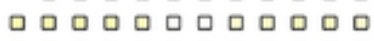
믐ㅁㅁㅁ 뭄ำ 믐ㅁㅁㅁ음 뭄ㅁㅁำ ロロロロロロロロロロロ ㅁㅁㅁㅁㅁㅁำ

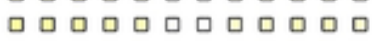

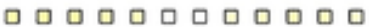

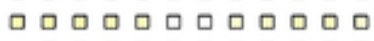

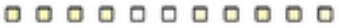

Temperature distribution of STEG at (a) $5 \mathrm{~min}$ (b) $15 \mathrm{~min}$ and front view of thermoelectric legs at (c) $5 \mathrm{~min}$ (d) $15 \mathrm{~min}$.

The three-dimensional temperature distribution of the STEG with PCM is shown in Fig. 12. It can be seen clearly that the temperature difference across the STEG with PCM decreased from $6.8^{\circ} \mathrm{C}$ (Fig. 12a) to $5.3{ }^{\circ} \mathrm{C}$ ( Fig. 11b) due to the decrease in solar radiation during the period of $5 \mathrm{~min}$ to $15 \mathrm{~min}$. This smaller decrease in temperature difference compared to that in Fig. 11 shows the capability of the PCM in providing stable performance for the STEG. In addition, Fig. 12c and Fig. 12d show the temperature distribution on the thermoelectric legs at $5 \mathrm{~min}$ and $15 \mathrm{~min}$ respectively. It is obvious that a uniform temperature distribution is achieved due to the presence of the PCM at the top surface of the solar thermoelectric generator. Consequently, the use of PCM provides a more stable performance from the STEG and nullifies the effects of non-uniform 
heat flux from solar concentrators especially at high radiation levels. Furthermore, the liquid fraction of the PCM with $5 \mathrm{~mm}$ height at $5 \mathrm{~min}$ and $15 \mathrm{~min}$ is shown in Fig. 13a and Fig. 13b respectively. It is obvious that a higher percentage of the PCM melts at $5 \mathrm{~min}$ compared to $15 \mathrm{~min}$ because of the fluctuations in solar radiation. In addition, at $5 \mathrm{~min}$, more than half of the PCM has melted while at $15 \mathrm{~min}$, most of the PCM is back in solid form. Similarly, the liquid fraction of the PCM with $10 \mathrm{~mm}$ height at $5 \mathrm{~min}$ and $15 \mathrm{~min}$ is shown in Fig. 13c and Fig. 13d respectively. It can be seen that although a larger percentage of the PCM melts at 5 min than at $15 \mathrm{~min}$, these percentage is still lower than that of the PCM with $5 \mathrm{~mm}$ height. Furthermore, Fig. 13 shows that the phase change starts close to the wall of the PCM fins and the melting front advances towards the center as time increases.

\section{Fig. 12}

h_pcm(1)=5 mm Time-5 min Volume: Temperature (degC)

(a)

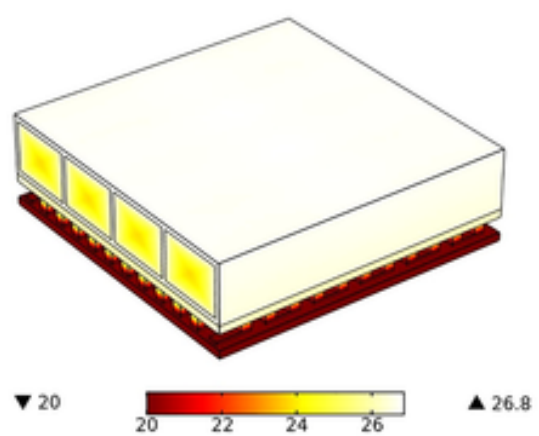

h_pcm(1) $=5$ mm Time-5 min Volume: Temperature (degC)

(c)

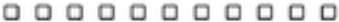

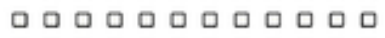

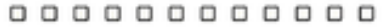
ロロロロロロロロロロ ロロロロロロロロロロ

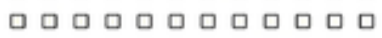
ロロロロロロロロロ ロ ロ ロ ロ ロ ロ ロ ㅁㅁㅁㅁㅁㅁ

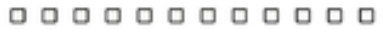
००

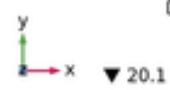

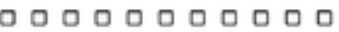

h_pcm(1) $=5 \mathrm{~mm}$ Time $=15 \mathrm{~min}$ Volume: Temperature (degC)

(b)

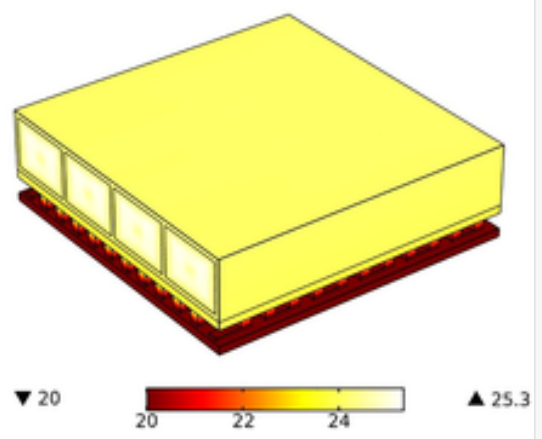

h_pcm(1)=5 mm Time=15 min Volume: Temperature (degC)

(d)

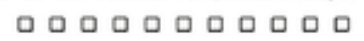

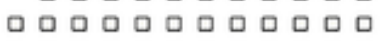

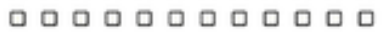

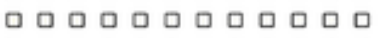

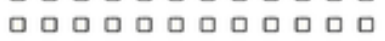

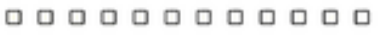
ロロロロロロロロロロ ロ ㅁㅁㅁㅁㅁㅁ ㅁㅁㅁㅁㅁㅁㅁㅁㅁ

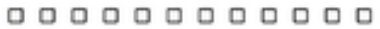
० ०

\footnotetext{
Temperature distribution of STEG with PCM at (a) 5 min (b) 15 min and front view of thermoelectric legs at (c) 5 min (d) 15 min.
} 
h_pcm(1)=5 mm Time=5 min Volume: Phase indicator, phase 2 (1)

(a)

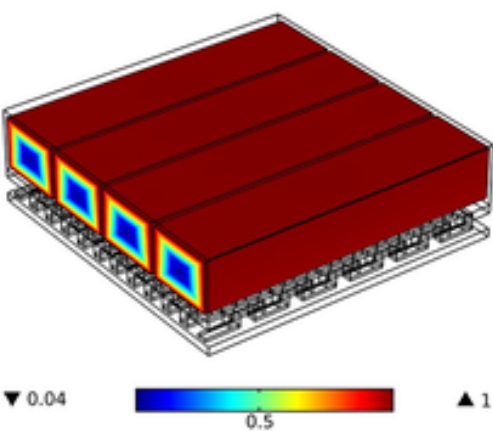

h_pcm(3)-10 mm Time-5 min Volume: Phase indicator, phase 2 (1)

(c)

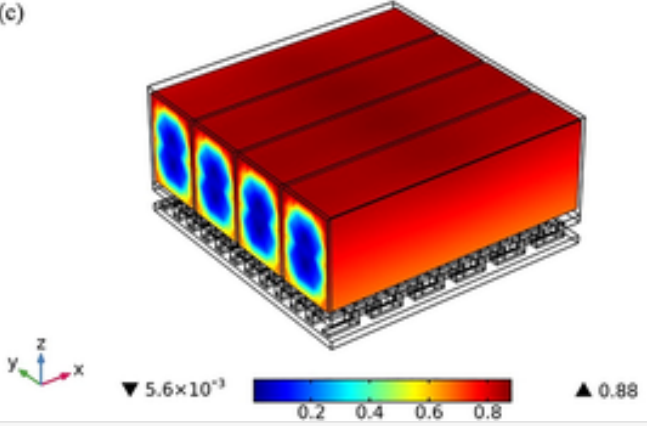

h_pcm(1) $=5 \mathrm{~mm}$ Time $=15 \mathrm{~min}$ Volume: Phase indicator, phase 2 (1)

(b)

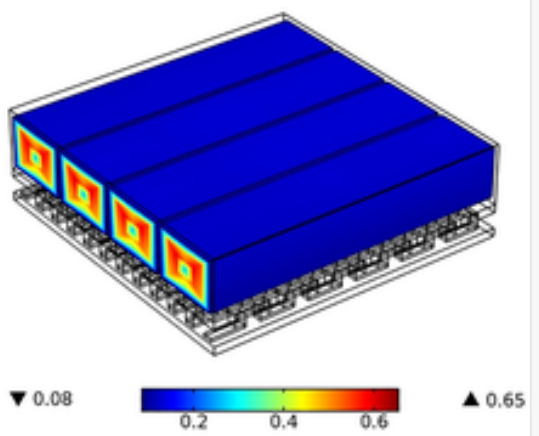

h_p cm(3)=10 mm Time-15 min Volume: Phase indicator, phase 2 (1)

(d)

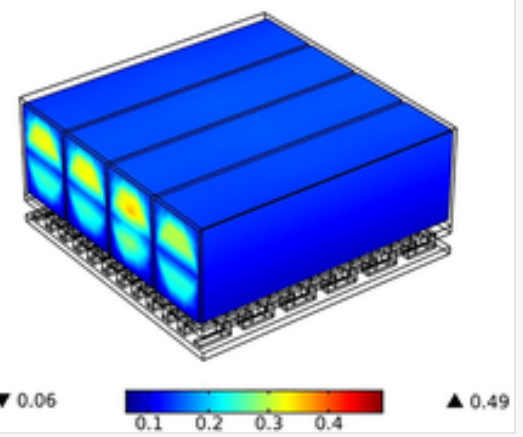

Liquid fraction of PCM with (a) $5 \mathrm{~mm}$ height, $5 \mathrm{~min}$ (b) $5 \mathrm{~mm}$ height, $15 \mathrm{~min}$ and (c) $10 \mathrm{~mm}$ height, $5 \mathrm{~min}$ (d) $10 \mathrm{~mm}$ height, $15 \mathrm{~min}$.

\section{Conclusion}

A detailed three-dimensional numerical investigation on the effect of transient and non-uniform heat flux on solar thermoelectric generator (STEG) performance was carried out in this study. COMSOL 5.4 Multiphysics software was used to perform the simulations based on finite element method and temperature dependent thermoelectric material properties were utilized. A comparison between the performance of a solar thermoelectric generator with and without phase change material (PCM) was made. In addition, a parametric study on the effects of PCM fin number and PCM height on the STEG performance with PCM was carried out. Subsequently, a comparison study was presented between a STEG with PCM, STEG with thick copper plate instead of PCM and conventional STEG without PCM or thick copper plate. Non-uniform heat flux from a compound parabolic concentrator simulated using Lighttools software was applied to the solar thermoelectric generator with and without PCM. Concentrated solar radiation is utilized in this study therefore, the average local concentration ratios across the surface of the solar selective absorber was multiplied with the varying solar radiation under typical partly cloudy weather condition for a period of time so as to increase the input solar energy to the solar thermoelectric generator and enhance its performance. The main conclusions from this study are:

1. Optimization of PCM fin is essential to obtaining an enhanced performance from the solar thermoelectric generator with phase change material.

2. The placement of PCM on the top surface of a solar thermoelectric generator is effective in providing a stable electrical performance from the STEG under varying weather conditions. 
3. The use of PCM on the top surface of a STEG has a great potential for protecting the solar thermoelectric generator when highly concentrated solar radiation is utilized.

4. The peak power output, temperature difference, and efficiency of the STEG decrease by $52.11 \%, 30.71 \%$ and $32.87 \%$ respectively, when the PCM height increased from $5 \mathrm{~mm}$ to $20 \mathrm{~mm}$.

5. The use of PCM with a solar thermoelectric generator can ensure the STEG still provides power output during periods of zero or very low solar radiation.

\section{Declaration of Competing Interest}

The authors declare that they have no known competing financial interests or personal relationships that could have appeared to influence the work reported in this paper.

\section{Acknowledgement}

This study was sponsored by the Project of EU Marie Curie International incoming Fellowships Program (745614).

\section{Appendix A Supplementary material}

Supplementary data to this article can be found online at https://doi.org/10.1016/j.applthermaleng.2020.115206.

\section{References}

The corrections made in this section will be reviewed and approved by a journal production editor. The newly added/removed references and its citations will be reordered and rearranged by the production team.

[1] Li G., Ma X., Shittu S., Zhao X., Solar thermoelectric technologies for power generation, in: Zhao X., Ma X. (Eds.), Adv. Energy Effic. Technol. Sol. Heating, Cool. Power Gener., Springer International Publishing, Cham, 2019, pp. 341-371.

[2] Li G., Diallo T.M.O., Akhlaghi Y.G., Shittu S., Zhao X., Ma X., Wang Y., Simulation and experiment on thermal performance of a micro-channel heat pipe under different evaporator temperatures and tilt angles, Energy 179 (2019) 549-557, doi:10.1016/j.energy.2019.05.040.

[3] Shittu S., Li G., Akhlaghi Y.G., Ma X., Zhao X., Ayodele E., Advancements in thermoelectric generators for enhanced hybrid photovoltaic system performance, Renew. Sustain. Energy Rev. 109 (2019) 24-54, doi:10.1016/j.rser.2019.04.023.

[4] Li G., Shittu S., Zhao X., Ma X., Preliminary experiment on a novel photovoltaic-thermoelectric system in summer, Energy 188 (2019), doi:10.1016/j.energy.2019.116041 116041. 
[5] Ando Junior O.H., Maran A.L.O., Henao N.C., A review of the development and applications of thermoelectric microgenerators for energy harvesting, Renew. Sustain. Energy Rev. 91 (2018) 376-393, doi:10.1016/j.rser.2018.03.052.

[6] Pandiyarajan V., Chinna Pandian M., Malan E., Velraj R., Seeniraj R.V., Experimental investigation on heat recovery from diesel engine exhaust using finned shell and tube heat exchanger and thermal storage system, Appl. Energy. 88 (2011) 77-87, doi:10.1016/j.apenergy.2010.07.023.

[7] Shittu S., Li G., Zhao X., Ma X., Akhlaghi Y.G., Ayodele E., Optimized high performance thermoelectric generator with combined segmented and asymmetrical legs under pulsed heat input power, J. Power Sources 428 (2019) 53-66, doi:10.1016/j.jpowsour.2019.04.099.

[8] Shittu S., Li G., Zhao X., Ma X., Akhlaghi Y.G., Ayodele E., High performance and thermal stress analysis of a segmented annular thermoelectric generator, Energy Convers. Manage. 184 (2019) 180-193, doi:10.1016/j.enconman.2019.01.064.

[9] Shittu S., Li G., Zhao X., Akhlaghi Y.G., Ma X., Yu M., Comparative study of a concentrated photovoltaic-thermoelectric system with and without flat plate heat pipe, Energy Convers. Manage. 193 (2019) 1-14, doi:10.1016/j.enconman.2019.04.055.

[10] Wang P., Wang K.F., Wang B.L., Cui Y.J., Modeling of thermoelectric generators with effects of side surface heat convection and temperature dependence of material properties, Int. J. Heat Mass Transf. 133 (2019) 1145-1153, doi:10.1016/j.ijheatmasstransfer.2019.01.006.

[11] Li G., Shittu S., Diallo T.M.O., Yu M., Zhao X., Ji J., A review of solar photovoltaicthermoelectric hybrid system for electricity generation, Energy 158 (2018) 41-58, doi:10.1016/j.energy.2018.06.021.

[12] Zhang M., Tian Y., Xie H., Wu Z., Wang Y., Influence of Thomson effect on the thermoelectric generator, Int. J. Heat Mass Transf. $137 \quad$ (2019) 1183-1190, doi:10.1016/j.ijheatmasstransfer.2019.03.155.

[13] Orr B., Akbarzadeh A., Mochizuki M., Singh R., A review of car waste heat recovery systems utilising thermoelectric generators and heat pipes, Appl. Therm. Eng. 101 (2016) 490-495, doi:10.1016/j.applthermaleng.2015.10.081.

[14] Shittu S., Li G., Zhao X., Zhou J., Ma X., Experimental study and exergy analysis of photovoltaic-thermoelectric with flat plate micro-channel heat pipe, Energy Convers. Manage. 207 (2020), doi:10.1016/j.enconman.2020.112515 112515.

[15] Li G., Zhang G., He W., Ji J., Lv S., Chen X., Chen H., Performance analysis on a solar concentrating thermoelectric generator using the micro-channel heat pipe array, Energy Convers. Manage. 112 (2016) 191-198, doi:10.1016/j.enconman.2016.01.025. 
[16] Li G., Shittu S., Ma X., Zhao X., Comparative analysis of thermoelectric elements optimum geometry between Photovoltaic-thermoelectric and solar thermoelectric, Energy 171 (2019) 599610, doi:10.1016/j.energy.2019.01.057.

[17] Champier D., Thermoelectric generators: A review of applications, Energy Convers. Manage. 140 (2017) 167-181, doi:10.1016/j.enconman.2017.02.070.

[18] Li G., Zhao X., Jin Y., Chen X., Ji J., Shittu S., performance analysis and discussion on the thermoelectric element footprint for PV-TE maximum power generation, J. Electron. Mater. 47 (2018) 5344-5351, doi:10.1007/s11664-018-6421-4.

[19] Shittu S., Li G., Zhao X., Ma X., Series of detail comparison and optimization of thermoelectric element geometry considering the PV effect, Renew. Energy 130 (2019) 930-942, doi:10.1016/j.renene.2018.07.002.

[20] Pereira A., Caroff T., Lorin G., Baffie T., Romanjek K., Vesin S., Kusiaku K., Duchemin H., Salvador V., Miloud-Ali N., Aixala L., Simon J., High temperature solar thermoelectric generator - indoor characterization method and modeling, Energy 84 (2015) 485-492, doi:10.1016/j.energy.2015.03.053.

[21] Sun D., Shen L., Yao Y., Chen H., Jin S., He H., The real-time study of solar thermoelectric generator, Appl. Therm. Eng. 119 (2017) 347-359, doi:10.1016/j.applthermaleng.2017.03.075.

[22] Mahmoudinezhad S., Rezania A., Cotfas P.A., Cotfas D.T., Rosendahl L.A., Transient behavior of concentrated solar oxide thermoelectric generator, Energy 168 (2019) 823-832, doi:10.1016/j.energy.2018.12.001.

[23] Kossyvakis D.N., Vossou C.G., Provatidis C.G., Hristoforou E.V., Computational analysis and performance optimization of a solar thermoelectric generator, Renew. Energy 81 (2015) 150161, doi:10.1016/j.renene.2015.03.026.

[24] Liu L., Sen Lu X., Shi M.L., Ma Y.K., Shi J.Y., Modeling of flat-plate solar thermoelectric generators for space applications, Sol. Energy $132 \quad$ (2016) 386-394, doi:10.1016/j.solener.2016.03.028.

[25] Jung Y.S., Jeong D.H., Kang S.B., Kim F., Jeong M.H., Lee K.S., Son J.S., Baik J.M., Kim J.S., Choi K.J., Wearable solar thermoelectric generator driven by unprecedentedly high temperature difference, Nano Energy 40 (2017) 663-672, doi:10.1016/j.nanoen.2017.08.061.

[26] Liu H.-B., Meng J.-H., Wang X.-D., Chen W.-H., A new design of solar thermoelectric generator with combination of segmented materials and asymmetrical legs, Energy Convers. Manage. 175 (2018) 11-20, doi:10.1016/j.enconman.2018.08.095.

[27] Li L., Gao X., Zhang G., Xie W., Wang F., Yao W., Combined solar concentration and carbon nanotube absorber for high performance solar thermoelectric generators, Energy Convers. 
Manage. 183 (2019) 109-115, doi:10.1016/j.enconman.2018.12.104.

[28] Lv S., He W., Hu Z., Liu M., Qin M., Shen S., Gong W., High-performance terrestrial solar thermoelectric generators without optical concentration for residential and commercial rooftops, Energy Convers. Manage. 196 (2019) 69-76, doi:10.1016/j.enconman.2019.05.089.

[29] Admasu B.T., Luo X., Yao J., Effects of temperature non-uniformity over the heat spreader on the outputs of thermoelectric power generation system, Energy Convers. Manage. 76 (2013) 533-540, doi:10.1016/j.enconman.2013.08.004.

[30] Ming T., Wang Q., Peng K., Cai Z., Yang W., Wu Y., Gong T., The influence of non-uniform high heat flux on thermal stress of thermoelectric power generator, Energies 8 (2015) 12584-12602, doi:10.3390/en81112332.

[31] Yin E., Li Q., Xuan Y., Effect of non-uniform illumination on performance of solar thermoelectric generators, Front. Energy 12 (2018) 239-248, doi:10.1007/s11708-018-0533-7.

[32] He W., Zhang G., Li G., Ji J., Analysis and discussion on the impact of non-uniform input heat flux on thermoelectric generator array, Energy Convers. Manage. 98 (2015) 268-274, doi:10.1016/j.enconman.2015.04.006.

[33] Jaworski M., Bednarczyk M., Czachor M., Experimental investigation of thermoelectric generator (TEG) with PCM module, Appl. Therm. Eng. 96 (2016) 527-533, doi:10.1016/j.applthermaleng.2015.12.005.

[34] Tu Y., Zhu W., Lu T., Deng Y., A novel thermoelectric harvester based on high-performance phase change material for space application, Appl. Energy 206 (2017) 1194-1202, doi:10.1016/j.apenergy.2017.10.030.

[35] Zhu W., Tu Y., Deng Y., Multi-parameter optimization design of thermoelectric harvester based on phase change material for space generation, Appl. Energy 228 (2018) 873-880, doi:10.1016/j.apenergy.2018.06.151.

[36] Ahmadi Atouei S., Ranjbar A.A., Rezania A., Experimental investigation of two-stage thermoelectric generator system integrated with phase change materials, Appl. Energy. 208 (2017) 332-343, doi:10.1016/j.apenergy.2017.10.032.

[37] Lee G., Kim C.S., Kim S., Kim Y.J., Choi H., Cho B.J., Flexible heatsink based on a phasechange material for a wearable thermoelectric generator, Energy 179 (2019) 12-18, doi:10.1016/j.energy.2019.05.018.

[38] Atouei S.A., Rezania A., Ranjbar A.A., Rosendahl L.A., Protection and thermal management of thermoelectric generator system using phase change materials: an experimental investigation, Energy 156 (2018) 311-318, doi:10.1016/j.energy.2018.05.109. 
Xuan Q., Li G., Pei G., Ji J., Su Y., Zhao B., Optimization design and performance analysis of a novel asymmetric compound parabolic concentrator with rotation angle for building application, Sol. Energy 158 (2017) 808-818, doi:10.1016/j.solener.2017.10.029.

[40] Mahmoudinezhad S., Rezania A., Rosendahl L.A., Behavior of hybrid concentrated photovoltaicthermoelectric generator under variable solar radiation, Energy Convers. Manage. 164 (2018) 443-452, doi:10.1016/j.enconman.2018.03.025.

[41] European Thermodynamics Limited, GM250-127-14-16 Thermoelectric generator module Datasheet, (2014) 1-4.

[42] Rubitherm Technologies GmbH, RT25HC, Tech. Data Sheet. (2020). https://www.rubitherm.eu/ media/products/datasheets/Techdata_RT25HC_EN_15012020.PDF (accessed January 28, 2020).

[43] Mankel C., Caggiano A., Koenders E., Thermal energy storage characterization of cementitious composites made with recycled brick aggregates containing PCM, Energy Build. 202 (2019), doi:10.1016/j.enbuild.2019.109395 109395.

[44] Xiao J., Yang T., Li P., Zhai P., Zhang Q., Thermal design and management for performance optimization of solar thermoelectric generator, Appl. Energy 93 (2012) 33-38, doi:10.1016/j.apenergy.2011.06.006.

[45] Machrafi H., An extended thermodynamic model for size-dependent thermoelectric properties at nanometric scales: Application to nanofilms, nanocomposites and thin nanocomposite films, Appl. Math. Model. 40 (2016) 2143-2160, doi:10.1016/j.apm.2015.09.044.

[46] E.E. Antonova, D.C. Looman, Finite elements for thermoelectric device analysis in ANSYS, in: ICT 2005. 24th Iinternational Conf. Thermoelectr., 2005: pp. 200-203. doi:http://doi.org/10.110 9/ICT.2005.1519922.

[47] Ezzat M.A., Theory of fractional order in generalized thermoelectric MHD, Appl. Math. Model. 35 (2011) 4965-4978, doi:10.1016/j.apm.2011.04.004.

[48] Li P., Cai L., Zhai P., Tang X., Zhang Q., Niino M., Design of a concentration solar thermoelectric generator, J. Electron. Mater. 39 (2010) 1522-1530, doi:10.1007/s11664-0101279-0.

[49] Li G., Zhou K., Song Z., Zhao X., Ji J., Inconsistent phenomenon of thermoelectric load resistance for photovoltaic-thermoelectric module, Energy Convers. Manage. 161 (2018) 155161, doi:10.1016/j.enconman.2018.01.079.

[50] Li G., Zhao X., Ji J., Conceptual development of a novel photovoltaic-thermoelectric system and preliminary economic analysis, Energy Convers. Manage. 126 (2016) 935-943, doi:10.1016/j.enconman.2016.08.074. 
Zhou J., Yi Q., Wang Y., Ye Z., Temperature distribution of photovoltaic module based on finite element simulation, Sol. Energy 111 (2015) 97-103, doi:10.1016/j.solener.2014.10.040.

[52] A. Kylili, M. Theodoridou, I. Ioannou, P.A. Fokaides, Numerical heat transfer analysis of Phase Change Material (PCM) -enhanced plasters, COMSOL Conf. Munich. (2016) 1-7. https://www.c omsol.com/paper/download/359131/fokaides_paper.pdf.

[53] COMSOL Multiphysics, Heat Transfer Module User's Guide, Version 5.4. (2018).

[54] Shittu S., Li G., Zhao X., Ma X., Akhlaghi Y.G., Fan Y., Comprehensive study and optimization of concentrated photovoltaic-thermoelectric considering all contact resistances, Energy Convers. Manage. 205 (2020), doi:10.1016/j.enconman.2019.112422 112422.

[55] Manikandan S., Selvam C., Pavan Sai Praful P., Lamba R., Kaushik S.C., Zhao D., Yang R., A novel technique to enhance thermal performance of a thermoelectric cooler using phase-change materials, J. Therm. Anal. Calorim. (2019), doi:10.1007/s10973-019-08353-y.

\section{Highlights}

- Effect of transient and non-uniform heat flux on STEG performance is studied.

- Comparison of STEG with and without PCM is made through simulation.

- A new design for STEG with PCM placed on top instead of heat sink is presented.

- Three-dimensional study of a full-scale solar thermoelectric generator is presented.

\section{Appendix A Supplementary material}

The following are the Supplementary data to this article:

Multimedia Component 1

Supplementary data 1

\section{Queries and Answers}


Query: Your article is registered as a regular item and is being processed for inclusion in a regular issue of the journal.

If this is NOT correct and your article belongs to a Special Issue/Collection please contact s.sekar@elsevier.com immediately prior to returning your corrections.

Answer: Yes

Query: The author names have been tagged as given names and surnames (surnames are highlighted in teal color).

Please confirm if they have been identified correctly.

Answer: Yes

Query: Please check the hierarchy of the section headings.

Answer: OK.

Query: Have we correctly interpreted the following funding source(s) and country names you cited in your article: Marie Curie, United Kingdom? /

Answer: Yes 